\title{
NMR shieldings from sum-over-states density-functional-perturbation theory: Further testing of the "Loc.3" approximation
}

\author{
Elisa Fadda ${ }^{a}$ \\ Département de Chimie, Université de Montréal, Case Postale 6128, Succursale Centre-ville, Montréal, \\ Québec H3C 3J7, Canada and Centre de Recherche en Calcul Appliqué (CERCA), \\ 5160 boulevard Décarie, bureau 400, Montréal, Québec H3X 2H9, Canada \\ Mark E. Casida \\ Laboratoire d'Etudes Dynamiques et Structurales de la Sélectivité (LEDSS), Université Joseph Fourier \\ (Grenoble I), 38041 Grenoble, France \\ Dennis R. Salahub \\ Département de Chimie, Université de Montréal, Case Postale 6128, Succursale Centre-ville, Montréal, \\ Québec H3C 3J7, Canada and Centre de Recherche en Calcul Appliqué (CERCA), \\ 5160 boulevard Décarie, bureau 400, Montréal, Québec H3X 2H9, Canada and University of Calgary, \\ Administration 110, 2500 University Drive N.W., Calgary, Alberta T2N 1N4, Canada
}

(Received 3 September 2002; accepted 24 January 2003)

The development and implementation of sum-over-states density-functional-perturbation theory (SOS-DFPT) [V.G. Malkin, O.L. Malkina, M.E. Casida, and D.R. Salahub, J. Am. Chem. Soc. 116, 5898 (1994)] has allowed a significant improvement in the accuracy of nuclear magnetic resonance (NMR) chemical shift values over the Hartree-Fock approximation. Furthermore, due to its computational efficiency, SOS-DFPT has opened the way to the study of systems of increased size compared to those that may be approached by more sophisticated but also computationally more intensive methods, such as Møller-Plesset perturbation theory or coupled-cluster theory. The success of SOS-DFPT relies on the introduction of an ad hoc correction to the excitation energy that improves the calculation of the paramagnetic component of the NMR shielding tensor. The lack of a clear physical basis for this approximation has left the SOS-DFPT open to some criticism. We have shown in a previous article [E. Fadda, M.E. Casida, and D.R. Salahub, Int. J. Quantum Chem. 91, 67 (2003)] that the electric field and magnetic field responses are given by equivalent expressions within the Tamm-Dancoff approximation of time-dependent density-functional theory (TD-DFT). This provides an SOS-DFPT expression which, upon restriction to diagonal contributions, yields a new rigorous "Loc.3" approximation. In this article, we more than double our original test set of 10 molecules for ${ }^{13} \mathrm{C},{ }^{15} \mathrm{~N}$, and ${ }^{17} \mathrm{O}$ chemical shifts to a set of 25 molecules. In addition, we compare the results of "Loc.3" SOS-DFPT with the results of promising recent functionals for DFT calculations of chemical shifts. The results show not only that the "Loc.3" approximation represents the rigorous physical connection between SOS-DFPT and TD-DFT, but also that it has very good potential for the prediction of NMR shielding constants, opening the way to further developments in DFT-based NMR parameter calculations. (c) 2003 American Institute of Physics. [DOI: 10.1063/1.1561047]

\section{INTRODUCTION}

In many applications density-functional theory (DFT) now represents the best compromise between computational accuracy and cost. The opportunity to include correlation in the self-consistent-field (SCF) calculations at a significantly smaller fraction of the computational time of highly correlated methods, such as Møller-Plesset (MP2) or coupledcluster (CC) theory, has allowed the development of DFT approximations to study various electronic properties and their widespread implementation in many software packages. In the case of the nuclear magnetic resonance (NMR) shielding tensor, numerous applications of DFT have been reported. ${ }^{1,2}$ One of the most successful approaches is the

${ }^{a)}$ Electronic mail: elisa@cerca.umontreal.ca sum-over-states density-functional-perturbation theory (SOS-DFPT) of Malkin et al. ${ }^{3}$ The most important innovation brought by this approach is the introduction of a correction to the excitation energy that greatly improves the evaluation of the paramagnetic component and ultimately of the whole NMR shielding tensor. These corrections are of two types: namely, local approximation 1, or "Loc.1," and local approximation 2, or "Loc.2." Both account for the change in exchange-correlation energy connected with the electronic transition from the ground state orbital " $k$ " to the excited state orbital " $a . " 1,3$ Even though the introduction of these corrections dramatically improves the results, regardless of the exchange-correlation functional used, ${ }^{4}$ SOS-DFPT has been criticized for lacking a clear theoretical justification. ${ }^{4-7}$

Jamorski et ${ }^{8}{ }^{8}$ observed that the approximate expression for the singlet-singlet excitation energy, obtained from 
the molecular implementation of time-dependent densityfunctional response theory (TD-DFRT), ${ }^{9}$ is very similar to that used in SOS-DFPT, in so far as only exchange and exchange-correlation integrals appear. In a previous article $\mathrm{e}^{10}$ we have shown that the SOS expression for electric perturbations, within the Tamm-Dancoff approximation (TDA), ${ }^{11}$ can also be used for magnetic perturbations. In this way we were able to derive a rigorous excitation energy expression that is analogous to the local approximation expressions in SOS-DFPT, but includes a new energy correction term, which we named "Loc.3."

The aim of this article is to present further testing of the "Loc.3" versus the "Loc.1," "Loc.2," and "UKS" approximations. Furthermore, we will also gauge the performance of "Loc.3" in the prediction of NMR isotropic shielding constants against four promising recent functionals for DFT calculations: the multiplicative Kohn-Sham (MKS) method from Wilson and Tozer, ${ }^{12}$ the $\mathrm{B}^{2} \mathrm{LYP}_{\mathrm{GGA}}^{0,05}$ from Wilson, Amos, and Handy, ${ }^{13,14}$ the PBE $0^{15-17}$ used in the calculations of Adamo and Barone ${ }^{18}$ and the self-interaction-corrected Vosko-Wilk-Nusair (SIC-VWN) functional from Patchkovskii, Autschbach, and Ziegler. ${ }^{6}$ All the tests have been conducted on a set of 25 small organic and inorganic molecules, for which we calculated the ${ }^{13} \mathrm{C},{ }^{15} \mathrm{~N}$, and ${ }^{17} \mathrm{O}$ isotropic and anisotropic NMR shieldings.

The results not only show that "Loc.3" represents the true physical connection between SOS-DFPT and TDDFT, but also that it has very good potential for the prediction of NMR shieldings.

\section{THEORETICAL BACKGROUND}

In this section we will briefly review the theory we presented in detail in Ref. 10.

A computationally convenient expression for the NMR shielding tensor can be derived from double perturbation theory: ${ }^{19,20}$

$$
\begin{aligned}
\sigma_{K}= & \left\langle\Psi_{0}\left|\mathbf{h}_{\mathbf{B M}_{K}}^{\mathrm{dia}}\right| \Psi_{0}\right\rangle \\
& -2 \sum_{I \neq 0} \frac{\left\langle\Psi_{0}\left|\mathbf{h}_{\mathbf{B}}^{\text {orb }}\right| \Psi_{I}\right\rangle\left\langle\Psi_{I}\left|\mathbf{h}_{\mathbf{M}_{K}}^{\mathrm{pso}}\right| \Psi_{0}\right\rangle}{E_{I}-E_{0}} .
\end{aligned}
$$

Here $\Psi_{0}$ and $\Psi_{I}$ represent, respectively, the ground state and excited singlet state wave functions and $E_{I}-E_{0}$ is the corresponding excitation energy, $\mathbf{M}_{K}$ indicates the magnetic moment of the nucleus $K$, and $\mathbf{B}$ is the magnetic field. Still in Eq. (2.1), the expectation value of the unperturbed state represents the diamagnetic contribution $\sigma^{d}$, where

$$
\mathbf{h}_{\mathbf{B}_{i} \mathbf{M}_{K_{j}}}^{\text {dia }}=\frac{e^{2}}{2 m c^{2}} \frac{\mathbf{r} \cdot\left(\mathbf{r}-\mathbf{R}_{K}\right) \delta_{i, j}-r_{j}\left(\mathbf{r}-\mathbf{R}_{K}\right)_{i}}{\left|\mathbf{r}-\mathbf{R}_{K}\right|^{3}},
$$

while, the SOS term accounts for the paramagnetic contribution $\sigma^{p}$ to the shielding tensor, where

$$
\mathbf{h}_{\mathbf{B}_{i}}^{\text {orb }}=-\frac{i e \hbar}{2 m c}(\mathbf{r} \times \boldsymbol{\nabla})_{i}
$$

represents the coupling between the magnetic field $\mathbf{B}$ and the orbital motion, and
TABLE I. Corrections to the excitation energy in SOS-DFPT.

\begin{tabular}{lc}
\hline \hline Ansatz & $\Delta E_{i \rightarrow a}^{x c}$ \\
\hline UKS $^{\text {a }}$ & $-\int \rho_{i}(\mathbf{r}) \frac{\delta \epsilon_{x c}^{L D A}(\mathbf{r})}{\delta \rho_{\uparrow}(\mathbf{r})} \rho_{a}(\mathbf{r}) d \mathbf{r}$ \\
Loc. 1 & $-\int \rho_{i}(\mathbf{r}) \frac{\delta v_{x c}^{\uparrow, L D A}(\mathbf{r})}{\delta \rho_{\uparrow}(\mathbf{r})} \rho_{a}(\mathbf{r}) d \mathbf{r}$ \\
\hline Loc. 2 & $+2 K_{k a}+\int \rho_{i}(\mathbf{r})\left(\frac{\delta v_{x c}^{\uparrow, L D A}(\mathbf{r})}{\delta \rho_{\uparrow}(\mathbf{r})}+\frac{\delta v_{x c}^{\uparrow, L D A}(\mathbf{r})}{\delta \rho_{\downarrow}(\mathbf{r})}\right) \rho_{a}(\mathbf{r}) d \mathbf{r}$
\end{tabular}

${ }^{\mathrm{a}}$ Uncoupled Kohn-Sham.

$$
\mathbf{h}_{\mathbf{M}_{K_{j}}}^{\mathrm{pso}}=-\frac{i e \hbar}{m c} \frac{\left[\left(\mathbf{r}-\mathbf{R}_{K}\right) \times \boldsymbol{\nabla}\right]_{j}}{\left|\mathbf{r}-\mathbf{R}_{K}\right|^{3}}
$$

represents the coupling between the nuclear magnetic moment $\mathbf{M}_{K}$ and the orbital motion. The evaluation of the paramagnetic term through the SOS expression is not straightforward, as it requires knowledge of excited state's wave functions and energies. In SOS-DFPT, ${ }^{1,3}$ the ground state wave function is approximated by a Slater determinant constructed from the occupied Kohn-Sham (KS) orbitals and the excited state wave function, corresponding to the electronic transition from the occupied orbital " $k$ " to the virtual orbital " $a$," is obtained substituting in the ground state Slater determinant the molecular orbital (MO) " $k$ " with the MO " $a$." The excitation energy can be, sometimes successfully, approximated just by the energy difference between the MO's involved in the transition [uncoupled Kohn-Sham (UKS)]. The success of SOS-DFPT is related to the introduction of two types of ad hoc corrections to the UKS excitation energy: namely, local approximation 1 ("Loc.1") and local approximation 2 ("Loc.2"), which are shown in Table I. The theoretical justification behind this approach can be found through time-dependent density-functional theory (TDDFT), which allows us to derive an exact expression for $\sigma^{p}$, analogous to the SOS term in Eq. (2.1). ${ }^{10}$ The paramagnetic component of the shielding tensor can be calculated from the response of the charge density to a time-dependent magnetic perturbation: hence, the excitation energies $\omega$, according to the SOS espression, are determined by the poles of $\sigma^{p}$ and are given by

$$
(\mathbf{A}+\mathbf{B})^{1 / 2}(\mathbf{A}-\mathbf{B})(\mathbf{A}+\mathbf{B})^{1 / 2} \mathbf{F}=\omega^{2} \mathbf{F},
$$

where

$$
A_{i a \sigma, j b \tau}=\delta_{i, j} \delta_{a, b} \delta_{\sigma, \tau}\left(\epsilon_{a \sigma}-\epsilon_{i \tau}\right)+K_{i a \sigma, j b \tau}
$$

and

$$
B_{i a \sigma, j b \tau}=K_{i a \sigma, j b \tau} .
$$

Here $\epsilon_{a \sigma}$ and $\epsilon_{i \tau}$ are Kohn-Sham orbital energies and $K_{i a \sigma, j b \tau}$ is the coupling matrix describing the linear response of the self-consistent field to a change in the Kohn-Sham density matrix. Equation (2.5) is equivalent to the expression that gives the excitation energies in the case of real perturbations, as electric field perturbations, although only the electric form is formally justified. ${ }^{10}$ However, the introduction of the TDA, ${ }^{11}$ which consists of setting $\mathbf{B}=0$, restores 


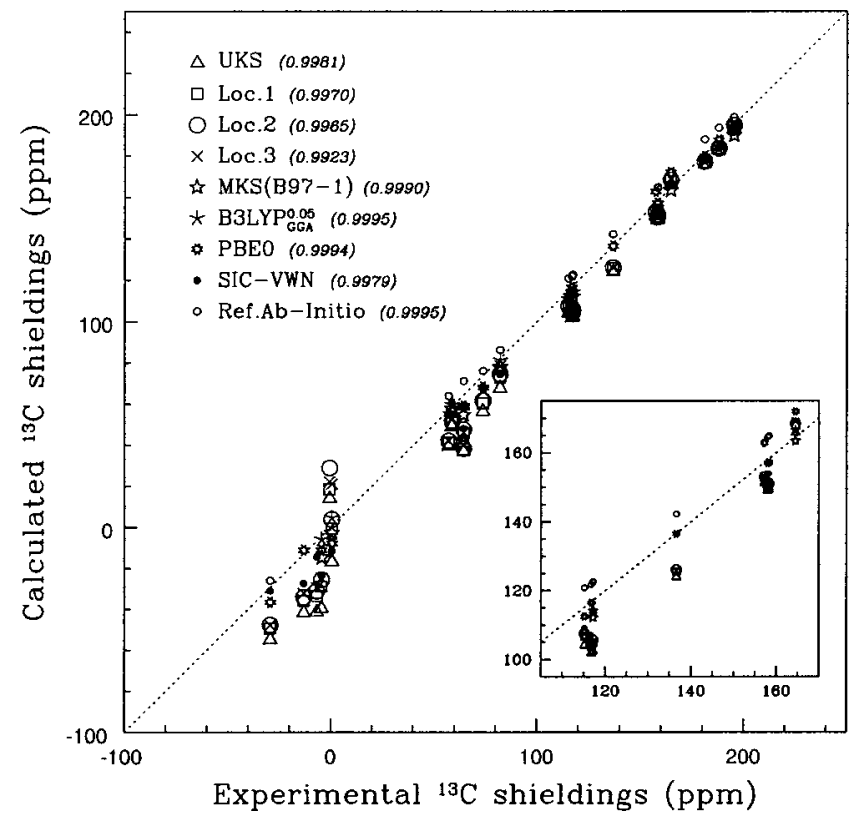

FIG. 1. Calculated NMR ${ }^{13} \mathrm{C}$ isotropic shieldings vs experimental reference. The correlation coefficients are reported in the legend in brackets. The box, located on the bottom right, represents an enlargement of the region of the diagram between 100 and $170 \mathrm{ppm}$.

the symmetry between magnetic and electric field perturbations. Therefore the excitation energies are given, in both cases, by

$$
\mathbf{A F}=\omega \mathbf{F},
$$

supporting the conclusion, derived by Autschbach et al., ${ }^{21,22}$ that the same equation system is obtained for both optical rotation and magnetizabilities. Thus the paramagnetic component is given, in the static limit, by

$$
\sigma^{p}(\omega, K)=2\left(\mathbf{h}^{\text {orb }}\right)^{\dagger} \mathbf{A}^{-1}\left[\left(\mathbf{h}^{\mathrm{pso}}\right)(K)\right],
$$

which represents the theoretical justification for SOS-DFPT. To obtain an expression for the excitation energy analogous to the "Loc.1" and "Loc.2," we have to introduce the twolevel model (2LM), which is equivalent to taking only the diagonal of the singlet coupled part of the A matrix. Within the 2LM framework each excitation is approximated by promotions from an occupied orbital " $k$ " to a virtual orbital " $a$ " to form a singlet state. Accordingly, the excitation energies are given by ${ }^{8,9}$

$$
\begin{aligned}
-\Delta E_{k \rightarrow a}= & \epsilon_{k}-\epsilon_{a}+\Delta E_{k \rightarrow a}^{x c} \\
= & \epsilon_{k}-\epsilon_{a}+2 K_{k a}+\int \rho_{k}(\mathbf{r}) \\
& \times\left(\frac{\partial v_{x c}^{\uparrow, \mathrm{LDA}}(\mathbf{r})}{\partial \rho_{\uparrow}(\mathbf{r})}+\frac{\partial v_{x c}^{\uparrow, \mathrm{LDA}}(\mathbf{r})}{\partial \rho_{\downarrow}(\mathbf{r})}\right) \rho_{a}(\mathbf{r}) d \mathbf{r},
\end{aligned}
$$

where $\Delta E_{k \rightarrow a}^{x c}$ represents the "Loc.3" correction. ${ }^{10}$

In the following sections we will present the results of further tests on the "Loc.3" approximation against "Loc.1"

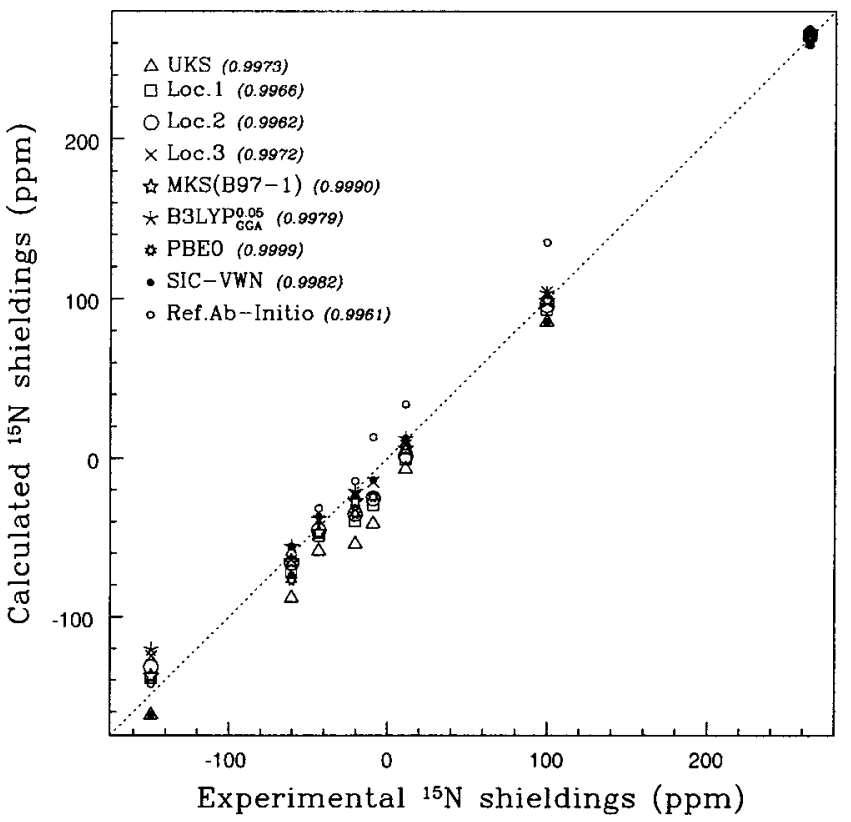

FIG. 2. Calculated NMR ${ }^{15} \mathrm{~N}$ isotropic shieldings vs experimental reference. The correlation coefficients are reported in the legend in brackets.

and "Loc.2" and we will compare its performance to that of some recently proposed functionals for the DFT calculation of NMR parameters.

\section{COMPUTATIONAL DETAILS}

All calculations have been performed within the DEMON suite of programs. The SCF calculations were performed with the version 3.5 of DEMON-KS (Ref. 23) and the timedependent calculations with version 3.1 of DEMONDYNARHO. The NMR shielding tensors have been calculated with the version 1.2 of DEMON-NMR, ${ }^{1,3}$ in which the gaugeorigin problem is solved by using the individual gauge for localized orbitals (IGLO) method developed by Kützelnigg et $a .^{24}$ In all calculations and for all atoms, we used the IGLO-III orbital basis set taken from the DEMON basis set library.

DEMON-KS and DEMON-DYNARHO make use of numerical grids and sets of auxiliary basis functions to evaluate exchange-correlation integrals and to eliminate four center integrals. The same grids and auxiliary basis functions were used in running the two programs. For the grid, we used the EXTRAFINE option (194 points per radial shell) in combination with a 64 point radial grid. The auxiliary basis functions used- $(5,2 ; 5,2)$ for all heavy atoms and $(5,1 ; 5,1)$ for hydrogen - were taken from the DEMON basis set library.

Contrary to the previous article,$^{10}$ we used only the local density approximation (LDA) exchange correlation functional, with the VWN parametrization, ${ }^{25}$ and the asymptotically Corrected LDA (AC-LDA). ${ }^{26,27}$ In fact, the "Loc.1," "Loc.2," and "Loc.3" corrections are always calculated using the LDA: thus, the most consistent choice is to use the $\operatorname{LDA} v_{x c}$. 


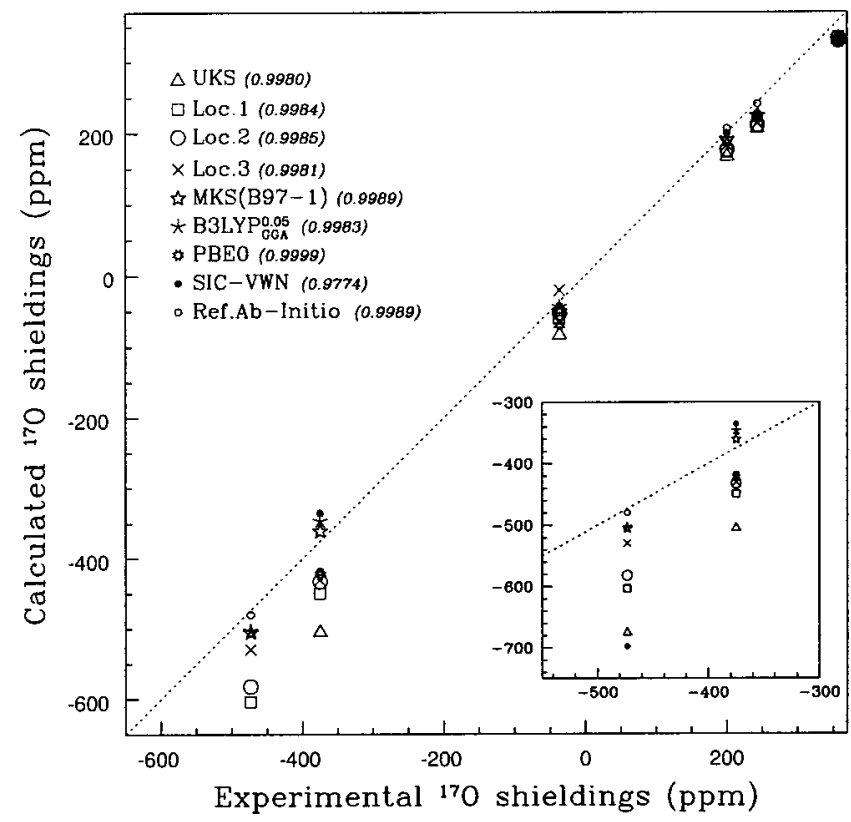

FIG. 3. Calculated NMR ${ }^{17} \mathrm{O}$ isotropic shieldings vs experimental reference. The correlation coefficients are reported in the legend in brackets. The box on the bottom right shows the location of the UKS and SIC-VWN ${ }^{17} \mathrm{O}$ shieldings relative to $\mathrm{N}_{2} \mathrm{O}$.

\section{RESULTS AND DISCUSSION}

In this section we will evaluate the isotropic and anisotropic shieldings obtained for 25 small organic and inorganic molecules, 10 of which were part of the calculations presented in our previous article. ${ }^{10}$

We chose to present and analyze the results as absolute shielding $\sigma_{\mathrm{abs}}$, and not to convert them to the shift scale, in order to avoid numerical biases. Furthermore, we are not interested, for the moment, in comparing our results with experimental chemical shifts, but mainly in validating the "Loc.3" approximation as the physical basis for SOS-DFPT through comparison with SOS-DFPT itself, with more sophisticated ab initio methods and with experimental absolute shielding constants. Nevertheless, good agreement with experimental and high quality ab initio data on the absolute shielding scale generally suggests also a good agreement on the shift scale.

The high quality $a b$ initio data, to which the isotropic shielding constants are referred to, are from the linearized coupled cluster doubles (LCCD) calculations from Cybulski and Bishop (Ref. 28), the second-order Møller-Plesset (MP2) perturbation theory calculation of Gauss (Ref. 29) and Stanton (Ref. 30). The reference for $\mathrm{CH}_{2} \mathrm{NN}$ was taken from a coupled-cluster singles and doubles augmented by a perturbative correction for connected triple excitations $[\operatorname{CCSD}(\mathrm{T})]$ calculation of Gauss and Stanton. ${ }^{31}$ The geometry of all molecules is the same as the one used to determine the chemical shielding reference value.

We first compare the SOS-DFPT calculations obtained with the four different approximations, and then we test the importance of the corrected asymptotic behavior with the use of the AC-LDA functional. Subsequently, we will analyze the performance of "Loc.3" versus the performance of four recent and promising functionals: the MKS method, ${ }^{12}$ the $\mathrm{B}^{2} \mathrm{LYP}_{\mathrm{GGA}}^{0.05},{ }^{13}$ the PBE0,${ }^{18}$ and the SIC-VWN. ${ }^{6}$

The statistical analysis of the isotropic shieldings have been performed through the calculation of the mean absolute error $(\bar{\delta})$, the standard deviation (SD) and the maximum deviation $(\max )$. The distribution of all of the calculated NMR shieldings against the experimental reference for ${ }^{13} \mathrm{C}$, ${ }^{15} \mathrm{~N}$, and ${ }^{17} \mathrm{O}$, and the corresponding correlation coefficients are shown in Figs. 1, 2, and 3, respectively.

An analogous statistical analysis of the anisotropic

TABLE II. Statistical analysis of the SOS-DFPT ${ }^{13} \mathrm{C},{ }^{15} \mathrm{~N}$, and ${ }^{17} \mathrm{O}$ NMR shielding constants calculated with the LDA $v_{x c}$ compared to high quality $a b$ initio and experimental shielding constants. All values are in ppm units.

\begin{tabular}{|c|c|c|c|c|c|c|c|c|}
\hline \multirow[b]{2}{*}{${ }^{13} \mathrm{C}$} & \multicolumn{4}{|c|}{ SOS-DFPT vs $a b$ initio } & \multicolumn{4}{|c|}{ SOS-DFPT vs experiment } \\
\hline & UKS & Loc. 1 & Loc. 2 & Loc. 3 & UKS & Loc. 1 & Loc. 2 & Loc. 3 \\
\hline $\bar{\delta}^{\mathrm{a}}$ & 21.4 & 17.2 & 15.8 & 15.6 & 15.6 & 12.0 & 11.2 & 11.5 \\
\hline $\mathrm{SD}^{\mathrm{b}}$ & 10.6 & 8.7 & 8.5 & 8.4 & 10.1 & 8.2 & 7.4 & 7.2 \\
\hline \multirow[t]{2}{*}{$\max ^{\mathrm{c}}$} & 45.8 & 35.1 & 32.4 & 30.9 & 35.3 & 26.9 & 26.1 & 24.4 \\
\hline & \multicolumn{4}{|c|}{ SOS-DFPT vs $a b$ initio } & \multicolumn{4}{|c|}{ SOS-DFPT vs experiment } \\
\hline${ }^{15} \mathrm{~N}$ & UKS & Loc.1 & Loc. 2 & Loc. 3 & UKS & Loc.1 & Loc. 2 & Loc. 3 \\
\hline $\bar{\delta}$ & 28.8 & 19.6 & 18.0 & 13.5 & 19.3 & 10.7 & 9.0 & 6.3 \\
\hline $\mathrm{SD}$ & 17.9 & 15.5 & 13.9 & 11.2 & 11.3 & 6.5 & 6.4 & 7.4 \\
\hline \multirow[t]{2}{*}{$\max$} & 54.5 & 42.4 & 38.9 & 30.8 & 33.8 & 20.1 & 17.3 & 24.2 \\
\hline & \multicolumn{4}{|c|}{ SOS-DFPT vs $a b$ initio } & \multicolumn{4}{|c|}{ SOS-DFPT vs experiment } \\
\hline${ }^{17} \mathrm{O}$ & UKS & Loc. 1 & Loc. 2 & Loc.3 & UKS & Loc. 1 & Loc. 2 & Loc. 3 \\
\hline $\bar{\delta}^{\mathrm{a}}$ & 68.4 & 43.5 & 36.8 & 31.2 & 79.7 & 52.2 & 43.9 & 33.0 \\
\hline $\mathrm{SD}^{\mathrm{b}}$ & 60.4 & 40.4 & 34.5 & 26.3 & 71.0 & 42.7 & 34.7 & 18.2 \\
\hline $\max ^{c}$ & 195.6 & 123.3 & 101.9 & 89.4 & 202.3 & 130.0 & 108.6 & 56.9 \\
\hline
\end{tabular}

${ }^{\mathrm{a}}$ Mean absolute error.

${ }^{\mathrm{b}} \mathrm{Standard}$ deviation.

${ }^{\mathrm{c}}$ Maximum deviation. 
TABLE III. ${ }^{13} \mathrm{C}$ shielding constant $(\mathrm{ppm})$ calculated with the LDA $v_{x c}$.

\begin{tabular}{|c|c|c|c|c|c|c|}
\hline \multirow[b]{2}{*}{ Molecule } & \multicolumn{4}{|c|}{ LDA } & \multirow[b]{2}{*}{$A b$ initio } & \multirow[b]{2}{*}{ Expt. $^{a}$} \\
\hline & UKS & Loc. 1 & Loc. 2 & Loc. 3 & & \\
\hline $\mathrm{CH}_{4}$ & 193.3 & 194.4 & 194.8 & 194.3 & $198.6^{\mathrm{b}}$ & 195.1 \\
\hline $\mathrm{CH}_{3} \mathrm{CH}_{3}$ & 176.2 & 177.0 & 177.3 & 176.8 & $188.0^{\mathrm{b}}$ & 180.9 \\
\hline $\mathrm{CH}_{3} \mathrm{CHO}$ & 151.2 & 152.5 & 153.0 & 153.1 & $162.8^{\mathrm{b}}$ & 157.2 \\
\hline $\mathrm{CH}_{3} \mathrm{COCH}_{3}$ & 149.0 & 150.0 & 150.4 & 150.4 & $164.5^{\mathrm{b}}$ & 158.0 \\
\hline $\mathrm{CH}_{3} \mathrm{CN}$ & 182.9 & 183.5 & 183.7 & 183.0 & $193.6^{\mathrm{b}}$ & 187.7 \\
\hline $\mathrm{CH}_{3} \mathrm{OH}$ & 124.0 & 125.6 & 126.1 & 125.8 & $142.2^{\mathrm{b}}$ & 136.6 \\
\hline $\mathrm{CH}_{3} \mathrm{NH}_{2}$ & 149.3 & 150.6 & 151.0 & 150.4 & $164.9^{\mathrm{b}}$ & 158.3 \\
\hline $\mathrm{CH}_{3} \mathrm{~F}$ & 101.9 & 103.7 & 104.2 & 103.5 & $121.8^{\mathrm{b}}$ & 116.8 \\
\hline $\mathrm{CH}_{2} \mathrm{CH}_{2}$ & 41.1 & 46.0 & 47.6 & 46.2 & $71.2^{\mathrm{b}}$ & 64.5 \\
\hline $\mathrm{CH}_{2} \mathrm{CCH}_{2}$ & 104.1 & 106.7 & 107.6 & 107.5 & $120.9^{\mathrm{b}}$ & 115.2 \\
\hline $\mathrm{CH}_{2} \mathrm{CCH}_{2}$ & -55.0 & -49.5 & -47.7 & -47.8 & $-26.0^{\mathrm{b}}$ & -29.3 \\
\hline $\mathrm{CHCH}$ & 102.4 & 104.9 & 105.7 & 105.2 & $122.6^{\mathrm{c}}$ & 117.2 \\
\hline $\mathrm{C}_{6} \mathrm{H}_{6}$ & 39.5 & 41.4 & 42.1 & 41.9 & $64.0^{\mathrm{b}}$ & 57.2 \\
\hline $\mathrm{HCN}$ & 67.7 & 73.0 & 74.6 & 78.4 & $86.3^{\mathrm{d}}$ & 82.1 \\
\hline $\mathrm{CH}_{3} \mathrm{CN}$ & 56.4 & 60.4 & 61.7 & 66.3 & $76.1^{\mathrm{b}}$ & 73.8 \\
\hline $\mathrm{HNC}$ & -0.5 & 13.9 & 18.2 & 28.9 & $28.5^{\mathrm{c}}$ & $\ldots$ \\
\hline $\mathrm{CH}_{2} \mathrm{NN}$ & 165.8 & 167.8 & 168.4 & 169.0 & $171.9^{\mathrm{d}}$ & $164.5^{\mathrm{d}}$ \\
\hline $\mathrm{HCHO}$ & -39.7 & -29.0 & -25.7 & -24.8 & $6.1^{\mathrm{c}}$ & $-4.4 \pm 3^{\mathrm{e}}$ \\
\hline $\mathrm{CH}_{3} \underset{\mathrm{CHO}}{ }$ & -41.5 & -33.6 & -31.2 & -29.5 & $1.2^{\mathrm{b}}$ & -6.7 \\
\hline $\mathrm{CH}_{3} \mathrm{COCH}_{3}$ & -41.8 & -36.0 & -34.2 & -32.3 & $-5.8^{\mathrm{b}}$ & -13.1 \\
\hline $\mathrm{CO}$ & -16.9 & -0.8 & 3.9 & 21.1 & $5.6^{\mathrm{d}}$ & $0.6^{\mathrm{d}}$ \\
\hline $\mathrm{CO}_{2}$ & 49.0 & 50.9 & 51.5 & 53.1 & $63.5^{\mathrm{b}}$ & 58.8 \\
\hline $\mathrm{CF}_{4}$ & 36.8 & 38.0 & 38.4 & 40.1 & $64.4^{\mathrm{b}}$ & 64.5 \\
\hline
\end{tabular}

${ }^{2}$ Experimental absolute shielding values from Ref. 32 unless otherwise specified.

${ }^{\mathrm{b}} \mathrm{MBPT}(2)$ from Ref. 29.

cL-CCD from Ref. 28

${ }^{\mathrm{d}} \operatorname{CCSD}(\mathrm{T})$ from Ref. 31.

${ }^{\mathrm{e}}$ Reference 12 .

TABLE IV. ${ }^{13} \mathrm{C}$ Anisotropic shieldings $\Delta \sigma$ (ppm) calculated with the LDA $v_{x c}$.

\begin{tabular}{|c|c|c|c|c|c|}
\hline \multirow[b]{2}{*}{ Molecule } & \multicolumn{4}{|c|}{ LDA } & \multirow[b]{2}{*}{ Ref. } \\
\hline & UKS & Loc. 1 & Loc. 2 & Loc. 3 & \\
\hline $\mathrm{CH}_{4}$ & 0.1 & 0.1 & 0.1 & 1.7 & $0.0^{\mathrm{a}}$ \\
\hline $\mathrm{CH}_{3} \mathrm{CH}_{3}$ & 17.0 & 16.9 & 16.9 & 17.1 & $\cdots$ \\
\hline $\mathrm{CH}_{3} \mathrm{CHO}$ & 55.8 & 54.0 & 54.9 & 54.2 & $\ldots$ \\
\hline $\mathrm{CH}_{3} \mathrm{COCH}_{3}$ & 63.6 & 63.1 & 62.9 & 62.7 & $\cdots$ \\
\hline $\mathrm{CH}_{3} \mathrm{CN}$ & 28.6 & 28.9 & 29.0 & 29.6 & $\cdots$ \\
\hline$\overline{\mathrm{C}} \mathrm{H}_{3} \mathrm{OH}$ & 87.7 & 86.8 & 86.5 & 86.4 & $\cdots$ \\
\hline $\mathrm{CH}_{3} \mathrm{NH}_{2}$ & 61.6 & 61.2 & 61.2 & 61.5 & $\cdots$ \\
\hline $\mathrm{CH}_{3} \mathrm{~F}$ & 122.5 & 121.0 & 120.6 & 120.8 & $\cdots$ \\
\hline $\mathrm{CH}_{2} \mathrm{CH}_{2}$ & 191.1 & 185.4 & 183.7 & 184.3 & $\cdots$ \\
\hline $\mathrm{CH}_{2} \mathrm{CCH}_{2}$ & 93.4 & 90.6 & 89.8 & 88.8 & $\cdots$ \\
\hline$\overline{\mathrm{C}} \mathrm{H}_{2} \mathrm{CCH}_{2}$ & 78.3 & 81.7 & 82.8 & 76.7 & $\cdots$ \\
\hline $\mathrm{CHCH}$ & 264.1 & 260.7 & 259.5 & 263.0 & $234.818^{b}$ \\
\hline $\mathrm{C}_{6} \mathrm{H}_{6}$ & 201.1 & 198.7 & 197.9 & 197.6 & $\cdots$ \\
\hline $\mathrm{HCN}$ & 315.5 & 307.8 & 305.3 & 301.1 & $288.5^{\mathrm{c}}$ \\
\hline $\mathrm{CH}_{3} \mathrm{CN}$ & 347.9 & 340.8 & 338.6 & 332.7 & $\ldots$ \\
\hline HNC & 410.7 & 389.1 & 382.7 & 371.9 & $368.84^{\mathrm{b}}$ \\
\hline $\mathrm{CH}_{2} \mathrm{NN}$ & 81.8 & 79.7 & 79.1 & 75.6 & $\ldots$ \\
\hline $\mathrm{HCHO}$ & 194.8 & 180.6 & 176.3 & 178.3 & $158.8^{\mathrm{c}}$ \\
\hline $\mathrm{CH}_{3} \mathrm{CHO}$ & 195.5 & 185.5 & 182.4 & 180.4 & $\ldots$ \\
\hline $\mathrm{CH}_{3} \mathrm{COCH}_{3}$ & 196.6 & 189.1 & 186.6 & 184.1 & $\ldots$ \\
\hline $\mathrm{CO}$ & 433.2 & 409.2 & 402.2 & 374.7 & $406.1^{\mathrm{d}}$ \\
\hline $\mathrm{CO}_{2}$ & 354.0 & 350.8 & 349.9 & 348.1 & $\cdots$ \\
\hline $\mathrm{CF}_{4}$ & 0.0 & 0.5 & 0.6 & 3.4 & $\cdots$ \\
\hline
\end{tabular}

${ }^{a}$ Experimental $\Delta \sigma$ cited in Ref. 28.

${ }^{\mathrm{b}} \mathrm{L}-\mathrm{CCD}$ from Ref. 28.

${ }^{\mathrm{c}} \mathrm{CCSD}(\mathrm{T})$ from Ref. 31

${ }^{\mathrm{d}}$ Experimental $\Delta$ cited in Ref. 12.
TABLE V. ${ }^{15} \mathrm{~N}$ shielding constant $(\mathrm{ppm})$ calculated with the LDA $v_{x c}$.

\begin{tabular}{|c|c|c|c|c|c|c|}
\hline \multirow[b]{2}{*}{ Molecule } & \multicolumn{4}{|c|}{ LDA } & \multirow[b]{2}{*}{$A b$ initio } & \multirow[b]{2}{*}{ Expt. $^{a}$} \\
\hline & UKS & Loc. 1 & Loc. 2 & Loc. 3 & & \\
\hline $\mathrm{NH}_{3}$ & 263.9 & 265.4 & 265.8 & 264.6 & $268.8^{\mathrm{b}}$ & $263.5^{\mathrm{e}}$ \\
\hline $\mathrm{CH}_{3} \mathrm{NH}_{2}$ & 262.6 & 264.5 & 265.1 & 264.1 & $261.2^{\mathrm{c}}$ & $\cdots$ \\
\hline $\mathrm{HNC}$ & 87.1 & 96.0 & 98.7 & 105.2 & $105.5^{\mathrm{b}}$ & $\cdots$ \\
\hline $\mathrm{HCN}$ & -54.2 & -39.7 & -35.2 & -23.8 & $-14.4^{\mathrm{b}}$ & $-20.4^{\mathrm{d}}$ \\
\hline $\mathrm{CH}_{3} \mathrm{CN}$ & -41.3 & -29.2 & -25.3 & -15.1 & $13.2^{\mathrm{c}}$ & $-9.1^{\mathrm{e}}$ \\
\hline $\mathrm{N}_{2}$ & -88.3 & -71.4 & -66.2 & -64.1 & $-55.7^{\mathrm{b}}$ & $-60.5^{\mathrm{e}}$ \\
\hline $\mathrm{CH}_{2} \mathrm{NN}$ & -58.4 & -48.7 & -45.6 & -39.2 & $-31.6^{\mathrm{d}}$ & $-43.4^{\mathrm{d}}$ \\
\hline $\mathrm{CH}_{2} \mathrm{NN}$ & -162.2 & -138.9 & -131.7 & -124.8 & $-142.4^{\mathrm{d}}$ & $-149.0^{\mathrm{d}}$ \\
\hline NNO & 85.6 & 93.6 & 96.2 & 104.3 & $135.1^{\mathrm{c}}$ & $99.5^{\mathrm{c}}$ \\
\hline NNO & -6.8 & -0.7 & 1.3 & 8.2 & $33.8^{\mathrm{c}}$ & $11.3^{\mathrm{c}}$ \\
\hline
\end{tabular}

${ }^{a}$ Experimental absolute shielding values.

${ }^{b}$ L-CCD calculation from Ref. 28.

${ }^{\mathrm{c}} \mathrm{MBPT}(2)$ calculation from Ref. 29.

${ }^{\mathrm{d}} \mathrm{CCSD}(\mathrm{T})$ calculation from Ref. 30

${ }^{\mathrm{e}}$ Reference 33 .

shieldings could not be performed, because the references available to us where too limited in number and from sources too diverse.

\section{A. Performance of the "Loc.3" compared to the other SOS-DFPT approximations}

The statistical analysis of the SOS-DFPT NMR isotropic shieldings for ${ }^{13} \mathrm{C},{ }^{15} \mathrm{~N}$, and ${ }^{17} \mathrm{O}$ calculated with the LDA $v_{x c}$ is reported in Table II.

The results obtained for ${ }^{13} \mathrm{C}$ indicate that the addition of any of the "Loc." corrections to the UKS approximation generally improves the accuracy, although all four approaches give comparable results for carbon atoms with only sigma bonds (see Table III). In fact, these systems are characterized by higher excitations where the exchange-only corrections are too small to give a significant contribution. The "Loc.1," "Loc.2," and "Loc.3" approaches become more important when we are dealing with unsaturated molecules, which are characterized by low-lying valence-type excitations. Nevertheless, the prediction of the ${ }^{13} \mathrm{C}$ shielding constant for carbonyl carbons and for carbon-carbon multiple bonds remains troublesome for all of the approaches. In fact, almost all the maximum deviation values, reported in Table

TABLE VI. ${ }^{15} \mathrm{~N}$ Anisotropic shieldings $\Delta \sigma(\mathrm{ppm})$ calculated with the LDA $v_{x c}$.

\begin{tabular}{|c|c|c|c|c|c|}
\hline \multirow[b]{2}{*}{ Molecule } & \multicolumn{4}{|c|}{ LDA } & \multirow[b]{2}{*}{ Ref. } \\
\hline & UKS & Loc. 1 & Loc. 2 & Loc. 3 & \\
\hline $\mathrm{NH}_{3}$ & 31.3 & 31.2 & 31.1 & 30.7 & $21.9^{\mathrm{a}}$ \\
\hline $\mathrm{CH}_{3} \mathrm{NH}_{2}$ & 65.4 & 65.0 & 65.0 & 65.7 & $\cdots$ \\
\hline $\mathrm{HNC}$ & 386.8 & 374.1 & 370.2 & 365.9 & $359.72^{\mathrm{b}}$ \\
\hline $\mathrm{HCN}$ & 589.5 & 568.4 & 561.8 & 554.0 & $528.9^{\mathrm{a}}$ \\
\hline $\mathrm{CH}_{3} \mathrm{CN}$ & 527.0 & 512.1 & 507.5 & 490.1 & $\ldots$ \\
\hline $\mathrm{N}_{2}$ & 640.7 & 615.6 & 607.9 & 604.3 & $596.5^{\mathrm{a}}$ \\
\hline $\mathrm{CH}_{2} \mathrm{NN}$ & 345.0 & 343.0 & 342.4 & 334.7 & $\cdots$ \\
\hline $\mathrm{CH}_{2} \mathrm{NN}$ & 224.8 & 204.2 & 198.1 & 203.6 & $\cdots$ \\
\hline NNO & 384.6 & 372.8 & 369.1 & 356.4 & $\ldots$ \\
\hline NNNO & 537.1 & 527.8 & 524.9 & 514.5 & $\ldots$ \\
\hline
\end{tabular}

${ }^{\mathrm{a}} \mathrm{CCSD}(\mathrm{T})$ calculation from Ref. 30.

${ }^{b}$ L-CCD calculation from Ref. 28. 
TABLE VII. ${ }^{17} \mathrm{O}$ shielding constant calculated with the LDA $v_{x c}$.

\begin{tabular}{crrrrrr}
\hline \hline & \multicolumn{7}{c}{ LDA } & & \\
\cline { 2 - 5 } Molecule & UKS & Loc. 1 & Loc. 2 & Loc. 3 & Ab initio & Expt. $^{\mathrm{a}}$ \\
\hline $\mathrm{CH}_{3} \mathrm{CHO}$ & -432.9 & -394.3 & -382.4 & -381.1 & $-291.7^{\mathrm{b}}$ & $\ldots$ \\
$\mathrm{CH}_{3} \mathrm{COCH}$ & -371.0 & -341.2 & -331.8 & -325.4 & $-279.8^{\mathrm{b}}$ & $\ldots$ \\
$\mathrm{CH}_{3} \mathrm{OH}$ & 323.1 & 325.1 & 325.7 & 326.1 & $350.6^{\mathrm{b}}$ & $\ldots$ \\
$\mathrm{HCHO}$ & -504.9 & -449.4 & -432.5 & -430.3 & $-418.0^{\mathrm{c}}$ & $-375 \pm 100^{\mathrm{d}}$ \\
$\mathrm{CO}$ & -83.9 & -60.1 & -53.0 & -20.9 & $-57.4^{\mathrm{c}}$ & $-36.7 \pm 17.2^{\mathrm{b}}$ \\
$\mathrm{CO}$ & 205.9 & 210.0 & 211.3 & 213.3 & $241.0^{\mathrm{b}}$ & $243.4^{\mathrm{d}}$ \\
$\mathrm{H}_{2} \mathrm{O}$ & 330.1 & 332.3 & 333.1 & 335.6 & $335.4^{\mathrm{c}}$ & $357.6 \pm 17.2^{\mathrm{b}}$ \\
$\mathrm{H}_{2} \mathrm{O}$ & 99.0 & 112.1 & 116.2 & 135.6 & $133.9^{\mathrm{c}}$ & $\ldots$ \\
$\mathrm{N}_{2} \mathrm{O}$ & 166.9 & 173.9 & 176.2 & 181.8 & $206.2^{\mathrm{b}}$ & $200.5^{\mathrm{e}}$ \\
$\mathrm{OF}_{2}$ & -675.4 & -603.1 & -581.7 & -529.2 & $-479.8^{\mathrm{b}}$ & $-473.1^{\mathrm{d}}$ \\
\hline \hline
\end{tabular}

${ }^{a}$ Experimental absolute shielding values.

${ }^{\mathrm{b}} \mathrm{CCSD}(\mathrm{T})$ calculation from Ref. 30

${ }^{\mathrm{C}} \mathrm{L}-\mathrm{CCD}$ calculation from Ref. 28.

${ }^{\mathrm{d}}$ Reference 13 .

${ }^{\text {e} M B P T(2) ~ c a l c u l a t i o n ~ f r o m ~ R e f . ~} 29$.

II, have been determined for carbonyl carbons: the only exception is represented by the case of the "Loc.3" and "Loc. 2" results when compared to the experimental reference, where the maximum deviation corresponds to $\mathrm{CF}_{4}$.

For CO, while "Loc.1" and "Loc.2" predict a ${ }^{13} \mathrm{C}$ shielding constant that is very close to the $a b$ initio and to the experimental value, "Loc.3" performs worse than all the other approximations. We believe this problem may be related with the breakdown of the two-level model (2LM) approximation in the TD-DFT calculation. This happens when symmetry considerations imply that more than two orbitals are needed to describe an excitation. In fact, for $\mathrm{CO}$, a spatial multiplet $\left(\Sigma^{+}+\Sigma^{-}+\Delta\right)$ is generated by the coupling between the $x$ and $y$ components of the $\pi$ orbitals.
TABLE VIII. ${ }^{17} \mathrm{O}$ Anisotropy shieldings (ppm) calculated with the LDA $v_{x c}$.

\begin{tabular}{crrrrc}
\hline \hline & \multicolumn{5}{c}{ LDA } \\
\cline { 2 - 4 } Molecule & \multicolumn{1}{c}{ UKS } & \multicolumn{1}{c}{ Loc. 1 } & Loc. 2 & Loc. 3 & Ref. \\
\hline $\mathrm{CH}_{3} \mathrm{CHO}$ & 1164.9 & 1109.9 & 1092.9 & 1094.1 & $\cdots$ \\
$\mathrm{CH}_{3} \mathrm{COCH}$ & 998.4 & 956.1 & 943.0 & 935.3 & $\cdots$ \\
$\mathrm{CH}_{3} \mathrm{OH}$ & 107.1 & 104.7 & 104.1 & 105.2 & $\cdots$ \\
$\mathrm{HCHO}$ & 1373.0 & 1291.8 & 1267.3 & 1269.0 & $1268.169^{\mathrm{a}}$ \\
$\mathrm{CO}$ & 739.6 & 704.8 & 694.5 & 651.4 & $694.6^{\mathrm{b}}$ \\
$\mathrm{CO}$ & 310.3 & 305.3 & 303.7 & 300.4 & $\cdots$ \\
$\mathrm{H}_{2} \mathrm{O}$ & 48.5 & 48.3 & 48.1 & 47.6 & $46.5^{\mathrm{b}}$ \\
$\mathrm{H}_{2} \mathrm{O}_{2}$ & 373.3 & 356.5 & 351.3 & 317.4 & $329.014^{\mathrm{a}}$ \\
$\mathrm{N}_{2} \mathrm{O}$ & 372.0 & 362.4 & 359.3 & 350.4 & $\cdots$ \\
$\mathrm{OF}_{2}$ & 252.8 & 198.2 & 183.0 & 163.9 & $\cdots$ \\
\hline \hline
\end{tabular}

${ }^{a}$ L-CCD calculation from Ref. 28.

${ }^{\mathrm{b}} \mathrm{CCSD}(\mathrm{T})$ calculation from Ref. 30 .

In Table IV are reported the ${ }^{13} \mathrm{C}$ anisotropic shieldings $\Delta \sigma=\sigma_{33}-1 / 2\left(\sigma_{11}+\sigma_{22}\right)$, calculated with the four different SOS-DFPT approaches. It can be noticed that the same conclusions derived for the ${ }^{13} \mathrm{C}$ isotropic shieldings are also suitable in the case of the ${ }^{13} \mathrm{C}$ anisotropic shieldings.

An interesting detail to point out is that, for the carbon atoms involved in double bonds with nitrogen, i.e., for nitriles and isonitiles groups, the "Loc.3" approximation introduces a noticeable improvement of the results and this is true not only for the ${ }^{13} \mathrm{C}$ but also for the ${ }^{15} \mathrm{~N}$ shielding constant (see Tables V and VI). Furthermore, from the statistical analysis, reported in Table II, it appears that, for the ${ }^{15} \mathrm{~N}$ shielding, the "Loc.3" approximation does better than "Loc.1," "Loc.2," and UKS. The only difficult case is given by the terminal nitrogen in diazomethane, to which are associated the maximum deviations for both "Loc.2" and

TABLE IX. Statistical analysis of the SOS-DFPT ${ }^{13} \mathrm{C},{ }^{15} \mathrm{~N}$, and ${ }^{17} \mathrm{O}$ NMR shielding constants calculated with the AC-LDA $v_{x c}$ compared to high quality $a b$ initio and experimental shielding constants. All values are in ppm units.

\begin{tabular}{|c|c|c|c|c|c|c|c|c|}
\hline \multirow[b]{2}{*}{${ }^{13} \mathrm{C}$} & \multicolumn{4}{|c|}{ SOS-DFPT vs $a b$ initio } & \multicolumn{4}{|c|}{ SOS-DFPT vs experiment } \\
\hline & UKS & Loc. 1 & Loc. 2 & Loc. 3 & UKS & Loc. 1 & Loc. 2 & Loc. 3 \\
\hline $\bar{\delta}^{\mathrm{a}}$ & 26.6 & 20.3 & 20.0 & 18.7 & 18.2 & 15.4 & 13.7 & 14.5 \\
\hline $\mathrm{SD}^{\mathrm{b}}$ & 15.0 & 11.8 & 10.3 & 9.9 & 12.5 & 10.0 & 8.1 & 8.6 \\
\hline \multirow[t]{2}{*}{$\max ^{c}$} & 55.2 & 46.6 & 43.9 & 42.0 & 47.3 & 38.7 & 36.0 & 34.1 \\
\hline & \multicolumn{4}{|c|}{ SOS-DFPT vs $a b$ initio } & \multicolumn{4}{|c|}{ SOS-DFPT vs experiment } \\
\hline${ }^{15} \mathrm{~N}$ & UKS & Loc. 1 & Loc. 2 & Loc.3 & UKS & Loc.1 & Loc. 2 & Loc. 3 \\
\hline $\bar{\delta}$ & 41.8 & 30.7 & 27.6 & 20.3 & 33.9 & 21.2 & 17.6 & 13.6 \\
\hline SD & 23.1 & 19.2 & 18.4 & 14.5 & 17.7 & 13.9 & 13.0 & 12.2 \\
\hline \multirow[t]{2}{*}{$\max$} & 78.1 & 64.8 & 60.6 & 49.9 & 59.7 & 42.5 & 38.3 & 28.4 \\
\hline & \multicolumn{4}{|c|}{ SOS-DFPT vs $a b$ initio } & \multicolumn{4}{|c|}{ SOS-DFPT vs experiment } \\
\hline${ }^{17} \mathrm{O}$ & UKS & Loc.1 & Loc. 2 & Loc.3 & UKS & Loc. 1 & Loc. 2 & Loc. 3 \\
\hline $\bar{\delta}^{\mathrm{a}}$ & 61.0 & 44.1 & 41.5 & 45.3 & 49.0 & 32.3 & 32.3 & 39.4 \\
\hline $\mathrm{SD}^{\mathrm{b}}$ & 63.1 & 47.8 & 43.2 & 43.4 & 40.8 & 25.0 & 16.8 & 19.6 \\
\hline $\max ^{\mathrm{c}}$ & 198.7 & 155.1 & 141.7 & 140.2 & 131.1 & 76.4 & 59.8 & 68.5 \\
\hline
\end{tabular}

${ }^{a}$ Mean absolute error.

${ }^{\mathrm{b}}$ Standard deviation.

${ }^{\mathrm{c}}$ Maximum deviation. 
TABLE X. ${ }^{13} \mathrm{C}$ shielding constant (ppm) calculated with the AC-LDA $v_{x c}$.

\begin{tabular}{|c|c|c|c|c|c|c|}
\hline \multirow[b]{2}{*}{ Molecule } & \multicolumn{4}{|c|}{ AC-LDA } & \multirow[b]{2}{*}{$A b$ initio } & \multirow[b]{2}{*}{ Expt. $^{\mathrm{a}}$} \\
\hline & UKS & Loc. 1 & Loc. 2 & Loc. 3 & & \\
\hline $\mathrm{CH}_{4}$ & 193.4 & 194.6 & 195.0 & 194.9 & $198.6^{\mathrm{b}}$ & 195.1 \\
\hline $\mathrm{CH}_{3} \mathrm{CH}_{3}$ & 174.6 & 175.5 & 175.8 & 175.2 & $188.0^{\mathrm{b}}$ & 180.9 \\
\hline $\mathrm{CH}_{3} \mathrm{CHO}$ & 148.0 & 149.5 & 149.9 & 150.1 & $162.8^{\mathrm{b}}$ & 157.2 \\
\hline $\mathrm{CH}_{3} \mathrm{COCH}_{3}$ & 148.9 & 150.0 & 150.3 & 150.3 & $164.5^{\mathrm{b}}$ & 158.0 \\
\hline $\mathrm{CH}_{3} \mathrm{CN}$ & 182.1 & 182.7 & 182.9 & 182.1 & $193.6^{\mathrm{b}}$ & 187.7 \\
\hline $\mathrm{CH}_{3} \mathrm{OH}$ & 119.9 & 121.6 & 122.1 & 122.0 & $142.2^{\mathrm{b}}$ & 136.6 \\
\hline $\mathrm{CH}_{3} \mathrm{NH}_{2}$ & 147.5 & 148.9 & 149.4 & 148.8 & $164.9^{\mathrm{b}}$ & 158.3 \\
\hline $\mathrm{CH}_{3} \mathrm{~F}$ & 98.4 & 100.3 & 100.9 & 100.5 & $121.8^{\mathrm{b}}$ & 116.8 \\
\hline $\mathrm{CH}_{2} \mathrm{CH}_{2}$ & 45.2 & 49.7 & 51.2 & 49.8 & $71.2^{\mathrm{b}}$ & 64.5 \\
\hline $\mathrm{CH}_{2} \mathrm{CCH}_{2}$ & 100.1 & 102.8 & 103.6 & 103.6 & $120.9^{b}$ & 115.2 \\
\hline$\overline{\mathrm{C}} \mathrm{H}_{2} \mathrm{CCH}_{2}$ & -55.9 & -50.4 & -48.6 & -48.8 & $-26.0^{\mathrm{b}}$ & -29.3 \\
\hline $\mathrm{CHCH}$ & 92.4 & 95.2 & 96.1 & 95.6 & $122.6^{\mathrm{c}}$ & 117.2 \\
\hline $\mathrm{C}_{6} \mathrm{H}_{6}$ & 40.1 & 42.0 & 42.7 & 42.5 & $64.0^{\mathrm{b}}$ & 57.2 \\
\hline $\mathrm{HCN}$ & 55.9 & 61.5 & 63.3 & 67.5 & $86.4^{\mathrm{c}}$ & 82.1 \\
\hline $\mathrm{CH}_{3} \mathrm{CN}$ & 47.3 & 51.8 & 53.2 & 58.3 & $76.1^{\mathrm{b}}$ & 73.8 \\
\hline HNC & -23.9 & -7.3 & -2.5 & 10.3 & $28.5^{\mathrm{c}}$ & $\ldots$ \\
\hline $\mathrm{CH}_{2} \mathrm{NN}$ & 165.5 & 167.5 & 168.1 & 170.3 & $171.9^{\mathrm{d}}$ & $164.5^{\mathrm{d}}$ \\
\hline $\mathrm{HCHO}$ & -37.0 & -27.0 & -23.9 & -23.0 & $6.1^{\mathrm{c}}$ & $-4.4 \pm 3^{e}$ \\
\hline $\mathrm{CH}_{3} \mathrm{CHO}$ & -54.0 & -45.4 & -42.7 & -40.8 & $1.2^{\mathrm{b}}$ & -6.7 \\
\hline $\mathrm{CH}_{3} \mathrm{COCH}_{3}$ & -56.1 & -49.5 & -47.5 & -45.3 & $-5.8^{\mathrm{b}}$ & -13.1 \\
\hline $\mathrm{CO}$ & -5.8 & 9.0 & 13.2 & 22.0 & $5.6^{\mathrm{d}}$ & $0.6^{\mathrm{d}}$ \\
\hline $\mathrm{CO}_{2}$ & 48.0 & 50.0 & 50.6 & 52.1 & $63.5^{\mathrm{b}}$ & 58.8 \\
\hline $\mathrm{CF}_{4}$ & 38.4 & 39.6 & 39.9 & 40.9 & $64.4^{\mathrm{b}}$ & 64.5 \\
\hline
\end{tabular}

${ }^{2}$ Experimental absolute shielding values from Ref. 32 unless otherwise specified.

${ }^{\mathrm{b}} \mathrm{MBPT}(2)$ calculation from Ref. 29

${ }^{c} \mathrm{~L}-\mathrm{CCD}$ calculation from Ref. 28.

${ }^{\mathrm{d}} \mathrm{CCSD}(\mathrm{T})$ calculation from Ref. 31.

${ }^{\mathrm{e}}$ Reference 12 .

"Loc.3." For all the other molecules the deviations of the isotropic shieldings calculated with "Loc.3," compared to the experimental reference, are not bigger than $6 \mathrm{ppm}$ : therefore, if we do not include the diazomethane in the statistical analysis, the mean absolute deviation and the standard deviation for the "Loc.3" approximation are lowered to $3.7 \mathrm{ppm}$ and $1.5 \mathrm{ppm}$, respectively. This is not the case for "Loc.1" and "Loc.2," which present difficulties also in the prediction of the ${ }^{15} \mathrm{~N}$ shielding of nitriles and isonitriles groups (see Table V).

Regarding the ${ }^{15} \mathrm{~N}$ anisotropic shieldings, reported in Table VI, the deviations from the reference values seem to be slightly larger than the ones determined for the corresponding ${ }^{15} \mathrm{~N}$ isotropic shieldings. Nevertheless, the "Loc.3" still represents an improvement over the other SOS-DFPT approximations.

The statistical analysis, in Table II, indicates that a much larger error is associated with the calculation of ${ }^{17} \mathrm{O}$ shielding constant for all four approximations, compared to the case of ${ }^{13} \mathrm{C}$ and ${ }^{15} \mathrm{~N}$. Nevertheless, the "Loc.3" approximation appears to improve slightly the results compared to "Loc.2" and outperforms "Loc.1" and UKS. This is mainly related to the better performance of the "Loc.3" approximation in the prediction of the ${ }^{17} \mathrm{O}$ shielding of $\mathrm{H}_{2} \mathrm{O}_{2}$ and of $\mathrm{OF}_{2}$ (see Table VII). The latter represents the most difficult case for all the approximations: however, the maximum deviation calculated for "Loc.3" is almost half of the maximum deviation calculated for "Loc.1" and "Loc.2." For the ${ }^{17} \mathrm{O}$ shielding of
TABLE XI. ${ }^{15} \mathrm{~N}$ shielding constant (ppm) calculated with the AC-LDA $v_{x c}$.

\begin{tabular}{crrrrrr}
\hline \hline & \multicolumn{7}{c}{ AC-LDA } & & \\
\cline { 2 - 5 } Molecule & \multicolumn{1}{c}{ UKS } & Loc. 1 & \multicolumn{1}{c}{ Loc. 2 } & Loc. 3 & Ab initio & Expt. $^{\mathrm{a}}$ \\
\hline $\mathrm{NH}_{3}$ & 256.4 & 258.1 & 256.6 & 257.7 & $268.8^{\mathrm{b}}$ & $263.5^{\mathrm{e}}$ \\
$\mathrm{CH}_{3} \mathrm{NH}_{2}$ & 265.8 & 267.5 & 268.0 & 267.5 & $261.2^{\mathrm{c}}$ & $\ldots$ \\
$\mathrm{HNC}$ & 78.5 & 88.9 & 92.0 & 99.8 & $105.5^{\mathrm{b}}$ & $\ldots$ \\
$\mathrm{HCN}$ & -61.3 & -46.1 & -41.4 & -29.3 & $-14.4^{\mathrm{b}}$ & $-20.4^{\mathrm{d}}$ \\
$\mathrm{CH}_{3} \mathrm{CN}$ & -64.9 & -51.6 & -47.4 & -36.7 & $13.2^{\mathrm{c}}$ & $-9.1^{\mathrm{e}}$ \\
$\mathrm{N}_{2}$ & -120.2 & -101.0 & -95.1 & -88.8 & $-55.7^{\mathrm{b}}$ & $-60.5^{\mathrm{e}}$ \\
$\mathrm{CH}_{2} \mathbf{N N}_{2}$ & -65.9 & -55.6 & -52.4 & -38.2 & $-31.6^{\mathrm{d}}$ & $-43.4^{\mathrm{d}}$ \\
$\mathrm{CH}_{2} \mathrm{NN}$ & -184.2 & -159.0 & -151.3 & -120.6 & $-142.4^{\mathrm{d}}$ & $-149.0^{\mathrm{d}}$ \\
$\mathbf{N N O}_{-}$ & 75.3 & 83.8 & 86.5 & 103.5 & $135.1^{\mathrm{c}}$ & $99.5^{\mathrm{c}}$ \\
$\mathrm{NNO}$ & -12.6 & -6.3 & -4.3 & 12.2 & $33.8^{\mathrm{c}}$ & $11.3^{\mathrm{c}}$ \\
\hline \hline
\end{tabular}

${ }^{a}$ Experimental absolute shielding values.

${ }^{\mathrm{b}} \mathrm{L}-\mathrm{CCD}$ calculation from Ref. 28.

${ }^{\mathrm{c}} \mathrm{MBPT}(2)$ calculation from Ref. 29.

${ }^{\mathrm{d}} \mathrm{CCSD}(\mathrm{T})$ calculation from Ref. 30

${ }^{\mathrm{e}}$ Reference 33

carbonyl groups, "Loc.2" and "Loc.3" perform equally well, but the error is still very large.

The ${ }^{17} \mathrm{O}$ anisotropic shieldings, reported in Table VIII, calculated with the "Loc." approximations are in fairly good agreement with the few available references. The "Loc.2" and "Loc.3" give the best performance, although "Loc.3" presents a significant deviation in the prediction of the ${ }^{17} \mathrm{O}$ anisotropic shielding for $\mathrm{CO}$.

\section{B. Role of the asymptotic behavior in the calculation of NMR shielding constants}

The effect of the asymptotic behavior on the calculation of NMR shielding constants has been tested with the use of the AC-LDA functional. ${ }^{26,27}$ The statistical analysis and the results for all nuclei are presented in Tables IX, X, XI, and XII. The effect of the AC-LDA does not radically change the performance of the SOS-DFPT. The ${ }^{13} \mathrm{C}$ is the less sensitive nucleus to the asymptotic behavior correction: in fact, the mean absolute error and the standard deviation are increased only by a few ppm units. The ${ }^{13} \mathrm{C}$ shielding constant is worst

TABLE XII. ${ }^{17} \mathrm{O}$ shielding constant calculated with the AC-LDA $v_{x c}$.

\begin{tabular}{|c|c|c|c|c|c|c|}
\hline \multirow[b]{2}{*}{ Molecule } & \multicolumn{4}{|c|}{ AC-LDA } & \multirow[b]{2}{*}{ Ab initio } & \multirow[b]{2}{*}{ Expt. $^{a}$} \\
\hline & UKS & Loc. 1 & Loc. 2 & Loc. 3 & & \\
\hline $\mathrm{CH}_{3} \mathrm{CHO}$ & -490.4 & -446.8 & -433.4 & -431.9 & $-291.7^{b}$ & $\cdots$ \\
\hline $\mathrm{CH}_{3} \mathrm{COCH}_{3}$ & -420.8 & -386.8 & -376.2 & -368.3 & $-279.8^{\mathrm{b}}$ & $\ldots$ \\
\hline $\mathrm{CH}_{3} \mathrm{OH}$ & 326.0 & 328.0 & 328.7 & 329.3 & $350.6^{\mathrm{b}}$ & $\ldots$ \\
\hline $\mathrm{HCHO}$ & -506.1 & -451.4 & -434.8 & -432.4 & $-418.0^{c}$ & $-375 \pm 100^{\mathrm{d}}$ \\
\hline $\mathrm{CO}$ & -56.3 & -35.1 & -28.7 & -11.0 & $-57.4^{\mathrm{c}}$ & $-36.7 \pm 17.2^{b}$ \\
\hline $\mathrm{CO}_{2}$ & 207.3 & 211.4 & 212.7 & 214.7 & $241.0^{\mathrm{b}}$ & $243.4^{\mathrm{d}}$ \\
\hline $\mathrm{H}_{2} \mathrm{O}$ & 317.8 & 320.4 & 321.2 & 320.0 & $335.4^{\mathrm{c}}$ & $357.6 \pm 17.2^{\mathrm{b}}$ \\
\hline $\mathrm{H}_{2} \mathrm{O}_{2}$ & 95.6 & 108.6 & 112.7 & 132.8 & $133.9^{c}$ & $\ldots$ \\
\hline $\mathrm{N}_{2} \mathrm{O}$ & 164.3 & 172.3 & 174.8 & 182.3 & $206.2^{\mathrm{b}}$ & $200.5^{\mathrm{e}}$ \\
\hline $\mathrm{OF}_{2}$ & -504.5 & -455.1 & -440.1 & -404.6 & $-479.8^{b}$ & $-473.1^{\mathrm{d}}$ \\
\hline
\end{tabular}

${ }^{a}$ Experimental absolute shielding values.

${ }^{\mathrm{b}} \mathrm{CCSD}(\mathrm{T})$ calculation from Ref. 30.

${ }^{c} \mathrm{~L}-\mathrm{CCD}$ calculation from Ref. 28.

${ }^{\mathrm{d}}$ Reference 13.

${ }^{\mathrm{e}} \mathrm{MBPT}(2)$ calculation from Ref. 29. 
TABLE XIII. Statistical analysis of ${ }^{13} \mathrm{C},{ }^{15} \mathrm{~N}$, and ${ }^{17} \mathrm{O}$ NMR shielding constants calculated with different DFT-based methods.

\begin{tabular}{|c|c|c|c|c|c|}
\hline \multirow[b]{2}{*}{${ }^{13} \mathrm{C}$} & \multicolumn{5}{|c|}{ DFT vs $a b$ initio } \\
\hline & Loc. 3 & $\mathrm{MKS}^{\mathrm{a}}$ & $\left(\mathrm{B} 3 \mathrm{LYP}_{\mathrm{GGA}}^{0.05}\right)^{\mathrm{b}}$ & $\mathrm{PBEO}^{\mathrm{c}}$ & SIC-VWN $^{\mathrm{d}}$ \\
\hline $\bar{\delta}^{\mathrm{e}}$ & 15.6 & 10.9 & 6.0 & 8.1 & 11.9 \\
\hline $\mathrm{SD}^{\mathrm{f}}$ & 8.4 & 5.1 & 3.5 & 3.5 & 6.0 \\
\hline \multirow[t]{3}{*}{$\max ^{g}$} & 30.9 & 20.8 & 11.9 & 17.2 & 29.9 \\
\hline & \multicolumn{5}{|c|}{ DFT vs experiment } \\
\hline & Loc. 3 & MKS & B3LYP & PBE0 & SIC-VWN \\
\hline $\bar{\delta}$ & 11.5 & 4.8 & 2.0 & 3.4 & 6.8 \\
\hline $\mathrm{SD}$ & 7.2 & 3.6 & 1.3 & 2.5 & 5.0 \\
\hline \multirow[t]{2}{*}{$\max$} & 24.4 & 10.3 & 4.1 & 7.3 & 19.4 \\
\hline & \multicolumn{5}{|c|}{ DFT vs $a b$ initio } \\
\hline${ }^{15} \mathrm{~N}$ & Loc. 3 & $\mathrm{MKS}^{\mathrm{a}}$ & $\left(\mathrm{BLYP}_{\mathrm{GGA}}^{0.05}\right)^{\mathrm{b}}$ & $\mathrm{PBEO}^{\mathrm{c}}$ & SIC-VWN $^{\mathrm{d}}$ \\
\hline $\bar{\delta}^{\mathrm{e}}$ & 13.5 & 16.2 & 11.6 & 19.5 & 19.7 \\
\hline $\mathrm{SD}^{\mathrm{f}}$ & 11.2 & 11.6 & 11.8 & 11.6 & 13.0 \\
\hline \multirow[t]{3}{*}{$\max ^{g}$} & 30.8 & 36.2 & 31.6 & 37.6 & 49.5 \\
\hline & \multicolumn{5}{|c|}{ DFT vs experiment } \\
\hline & Loc. 3 & MKS & $\mathrm{B} 3 \mathrm{LYP}_{\mathrm{GGA}}^{0.05}$ & PBE0 & SIC-VWN \\
\hline $\bar{\delta}$ & 6.3 & 4.8 & 6.5 & 8.8 & 7.6 \\
\hline $\mathrm{SD}$ & 7.4 & 3.6 & 9.8 & 7.3 & 5.0 \\
\hline \multirow[t]{2}{*}{$\max$} & 24.2 & 11.5 & 28.4 & 15.3 & 13.9 \\
\hline & \multicolumn{5}{|c|}{ DFT vs $a b$ initio } \\
\hline${ }^{17} \mathrm{O}$ & Loc. $3^{\mathrm{g}}$ & $\mathrm{MKS}^{\mathrm{a}}$ & $\left(\mathrm{B} 3 \mathrm{LYP}_{\mathrm{GGA}}^{0.05}\right)^{\mathrm{b}}$ & $\mathrm{PBEO}^{\mathrm{c}}$ & SIC-VWN ${ }^{\mathrm{d}, \mathrm{h}}$ \\
\hline $\bar{\delta}^{\mathrm{e}}$ & 31.2 & 21.2 & 22.2 & 18.4 & 47.8 \\
\hline $\mathrm{SD}^{\mathrm{f}}$ & 26.3 & 19.2 & 22.8 & 16.8 & 68.1 \\
\hline \multirow[t]{3}{*}{$\max ^{\mathrm{g}}$} & 89.4 & 57.4 & 71.6 & 50.4 & 218.0 \\
\hline & \multicolumn{5}{|c|}{ DFT vs experiment } \\
\hline & Loc. 3 & MKS & B3LYP $\mathrm{GGA}_{\mathrm{GG}}^{0.05}$ & PBE0 & SIC-VWN $^{\mathrm{b}}$ \\
\hline $\bar{\delta}$ & 33.0 & 19.6 & 19.6 & 33.2 & 53.6 \\
\hline $\mathrm{SD}$ & 18.2 & 8.4 & 9.5 & 10.2 & 85.2 \\
\hline $\max$ & 56.1 & 31.9 & 29.4 & 47.2 & 224.7 \\
\hline
\end{tabular}

${ }^{\mathrm{a}} \mathrm{MKS}(\mathrm{B} 97-1)$ from Ref. 12.

${ }^{\mathrm{b}}$ Reference 13.

'Reference 18.

${ }^{\mathrm{d}}$ Reference 6 .

${ }^{\mathrm{e}}$ Mean absolute error.

${ }^{\mathrm{f}}$ Standard deviation.

${ }^{g}$ Maximum deviation.

only in the case of the carbonyl carbon of $\mathrm{CH}_{3} \mathrm{CHO}$, which corresponds to the maximum deviation for all approximations. The ${ }^{15} \mathrm{~N}$ is slightly more effected by the asymptotic correction: the mean absolute error is increased from 6.8 ppm, for "Loc.3," up to $14.6 \mathrm{ppm}$, for UKS. The worst cases are given by $\mathrm{CH}_{3} \mathrm{CN}$ and $\mathrm{N}_{2}$, to which are associated the maximum deviations for all the approximations, even in the case of the "Loc.3," which, as we remarked in the previous section, showed a great improvement in the prediction of ${ }^{15} \mathrm{~N}$ shielding for nitriles groups with the LDA functional. The case of ${ }^{17} \mathrm{O}$ shielding is more difficult to evaluate. From a close comparison with the results obtained with the LDA functional (see Tables VII and XII), we can see that the asymptotic correction worsens the performance in the case of $\mathrm{CH}_{3} \mathrm{CHO}, \mathrm{CH}_{3} \mathrm{COCH}_{3}$, and $\mathrm{H}_{2} \mathrm{O}$, does not play a significant role in the case of $\mathrm{CH}_{3} \mathrm{OH}, \mathrm{HCHO}, \mathrm{CO}, \mathrm{CO}_{2}, \mathrm{H}_{2} \mathrm{O}_{2}$, and $\mathrm{N}_{2} \mathrm{O}$, and that greatly improves the prediction for $\mathrm{OF}_{4}$, except in the case of "Loc.3."

On the basis of these results, our conclusion is that the determination of the NMR shielding constant, independently of the nuclei, is only slightly influenced by the improved description of the higher and Rydberg excitations, in agreement with the observations in Refs. 4 and 12. The only exceptions are given by $\mathrm{CH}_{3} \mathrm{CN}$ and $\mathrm{N}_{2}$, where the ${ }^{15} \mathrm{~N}$ shielding constant are made significantly worse by the AC-LDA, 
TABLE XIV. ${ }^{13} \mathrm{C}$ shielding constant (ppm) calculated with the LDA $v_{x c}$.

\begin{tabular}{|c|c|c|c|c|c|c|c|}
\hline Molecule & Loc. 3 & $\mathrm{MKS}^{\mathrm{a}}$ & $\left(\mathrm{B} 3 \mathrm{LYP}_{\mathrm{GGA}}^{0.05}\right)^{\mathrm{b}}$ & $\mathrm{PBEO}^{\mathrm{c}}$ & SIC-VWN ${ }^{\mathrm{d}}$ & Ab initio & Expt. $^{\mathrm{e}}$ \\
\hline $\mathrm{CH}_{4}$ & 194.3 & 189.9 & 193.1 & 194.0 & 191.5 & $198.6^{\mathrm{f}}$ & 195.1 \\
\hline $\mathrm{CH}_{3} \mathrm{CH}_{3}$ & 176.8 & $\cdots$ & $\cdots$ & 179.7 & 177.7 & $188.0^{\mathrm{f}}$ & 180.9 \\
\hline $\mathrm{CH}_{3} \mathrm{CHO}$ & 153.1 & $\cdots$ & $\cdots$ & $\cdots$ & 152.5 & $162.8^{\mathrm{f}}$ & 157.2 \\
\hline $\mathrm{CH}_{3} \mathrm{COCH}_{3}$ & 150.4 & $\vdots$ & $\cdots$ & 157.0 & 153.9 & $164.5^{f}$ & 158.0 \\
\hline $\mathrm{CH}_{3} \mathrm{CN}$ & 183.0 & $\cdots$ & $\cdots$ & 187.7 & 183.8 & $193.6^{\mathrm{f}}$ & 187.7 \\
\hline $\mathrm{CH}_{3} \mathrm{OH}$ & 125.8 & $\cdots$ & $\ldots$ & 136.5 & $\cdots$ & $142.2^{\mathrm{f}}$ & 136.6 \\
\hline $\mathrm{CH}_{3} \mathrm{NH}_{2}$ & 150.4 & $\ldots$ & $\ldots$ & 157.1 & 153.9 & $164.9^{\mathrm{f}}$ & 158.3 \\
\hline $\mathrm{CH}_{3} \mathrm{~F}$ & 103.5 & $\cdots$ & $\ldots$ & 116.5 & 107.1 & $121.8^{\mathrm{f}}$ & 116.8 \\
\hline $\mathrm{CH}_{2} \mathrm{CH}_{2}$ & 46.2 & 54.8 & $\cdots$ & 58.4 & 58.0 & $71.2^{\mathrm{f}}$ & 64.5 \\
\hline $\mathrm{CH}_{2} \mathrm{CCH}_{2}$ & 107.5 & $\cdots$ & $\cdots$ & 112.5 & 109.2 & $120.9^{\mathrm{f}}$ & 115.2 \\
\hline$\overline{\mathrm{CH}}_{2} \mathrm{CCH}_{2}$ & -47.8 & $\cdots$ & $\cdots$ & -36.6 & -31.1 & $-26.0^{\mathrm{f}}$ & -29.3 \\
\hline $\mathrm{CHCH}$ & 105.2 & 112.1 & 114.2 & 114.0 & 113.7 & $122.6^{\mathrm{g}}$ & 117.2 \\
\hline $\mathrm{C}_{6} \mathrm{H}_{6}$ & 41.9 & $\ldots$ & $\cdots$ & 55.3 & 54.9 & $64.0^{\mathrm{f}}$ & 57.2 \\
\hline $\mathrm{HCN}$ & 78.4 & 78.0 & 81.3 & 76.6 & 74.4 & $86.3^{\text {h }}$ & 82.1 \\
\hline $\mathrm{CH}_{3} \underline{\mathrm{CN}}$ & 66.3 & $\cdots$ & $\ldots$ & 68.2 & 67.4 & $76.1^{f}$ & 73.8 \\
\hline HNC & 28.9 & $\cdots$ & 22.2 & $\cdots$ & $\cdots$ & $28.5^{\mathrm{g}}$ & $\cdots$ \\
\hline $\mathrm{CH}_{2} \mathrm{NN}$ & 169.0 & 163.4 & 166.5 & $\ldots$ & 166.5 & $171.9^{\mathrm{h}}$ & $164.5^{\mathrm{h}}$ \\
\hline $\mathrm{HCHO}$ & -24.8 & -14.7 & -5.8 & -11.1 & -23.8 & $6.1^{\mathrm{g}}$ & $-4.4 \pm 3^{a}$ \\
\hline $\mathrm{CH}_{3} \mathrm{CHO}$ & -29.5 & $\ldots$ & $\ldots$ & $\ldots$ & -14.4 & $1.2^{\mathrm{f}}$ & -6.7 \\
\hline $\mathrm{CH}_{3} \mathrm{COCH}_{3}$ & -32.3 & $\ldots$ & $\ldots$ & -11.1 & -27.4 & $-5.8^{\mathrm{f}}$ & -13.1 \\
\hline $\mathrm{CO}$ & 21.1 & -2.7 & 4.7 & -7.8 & -11.6 & $5.6^{\mathrm{h}}$ & $0.6^{\mathrm{h}}$ \\
\hline $\mathrm{CO}_{2}$ & 53.1 & 57.9 & 59.7 & 56.8 & 61.0 & $63.5^{\mathrm{f}}$ & 58.8 \\
\hline $\mathrm{CF}_{4}$ & 40.1 & $\cdots$ & $\ldots$ & 59.2 & 48.1 & $64.4^{\mathrm{f}}$ & 64.5 \\
\hline
\end{tabular}

${ }^{\mathrm{a}} \mathrm{MKS}(\mathrm{B} 97-1)$ from Ref. 12.

${ }^{\mathrm{b}}$ Reference 13 .

${ }^{\mathrm{c}}$ Reference 18 .

${ }^{\mathrm{d}}$ Reference 6.

${ }^{e}$ Experimental absolute shielding values from Ref. 32 unless otherwise specified.

${ }^{\mathrm{f}} \mathrm{MBPT}(2)$ calculation or expt. from Ref. 29.

${ }^{g} \mathrm{~L}-\mathrm{CCD}$ calculation or expt. from Ref. 28.

${ }^{\mathrm{h}} \mathrm{CCSD}(\mathrm{T})$ calculation or expt. from Ref. 31.

and by $\mathrm{OF}_{4}$, for which the ${ }^{17} \mathrm{O}$ shielding is much improved by the AC-LDA.

\section{Performance of the "Loc.3" approximation compared to other DFT-based methods}

The results obtained with the "Loc.3" approximation are here compared to four of the most recent and promising functionals for NMR shielding calculations. These are the MKS method, ${ }^{12}$ for which we chose the results obtained using the B97-1 functional ${ }^{34,35}$ to determine the reference density, the $\mathrm{B} 3 \mathrm{LYP}_{\mathrm{GGA}}^{0,05}$ functional, ${ }^{13,14}$ where the 0.05 represents the value of the "exact-exchange" coefficient $C_{X}$, the PBE0,${ }^{15-17}$ and the SIC-VWN functionals. ${ }^{6}$

Before proceeding with the analysis of the results, it is important to point out that, since the MKS(B97-1), B3LYP GGA $^{0,05}$, PBE0, and SIC-VWN NMR shieldings have been taken from the original referenced articles, all the calculations have been performed with different, although all sufficiently large, basis sets. Pertaining to the molecular geometries, all of the NMR calculations were performed on systems with a structure determined by high level theoretical calculation: ${ }^{6,13,28,29,36}$ therefore, differences of NMR shieldings derived from differences in the molecular geometries are expected to be rather small.

The statistical analysis of the results is shown in Table XIII, while the ${ }^{13} \mathrm{C},{ }^{15} \mathrm{~N}$, and ${ }^{17} \mathrm{O}$ NMR shielding constants are reported in Tables XIV, XV, and XVI, respectively.
The results obtained for ${ }^{13} \mathrm{C}$ with "Loc.3" are fairly good, considering that have been obtained with the LDA functional, although, as we remarked in the previous sections, the "Loc.3" approximation is still of limited accuracy for multiple bonded carbons. From Table XIV, we can observe that this problem is partly solved by the use of more advanced functionals, for which the only difficult case seems to be represented by $\mathrm{HCHO}$.

For the ${ }^{15} \mathrm{~N}$ nucleus, the picture is quite different. The "Loc.3" approximation offers the same level of accuracy than all the other methods and its performance is very close to the one given by the SIC-VWN, except for the ${ }^{15} \mathrm{~N}$ shielding of the external nitrogen atom of $\mathrm{N}_{2} \mathrm{O}$, for which the SIC-VWN presents a quite larger deviation (see Table XV). Furthermore, the "Loc.3" performance is superior to the PBE0 in determining the ${ }^{15} \mathrm{~N}$ shielding for nitriles group. The only difficult cases are represented by the terminal nitrogen in $\mathrm{CH}_{3} \mathrm{NN}$ and $\mathrm{N}_{2} \mathrm{O}$, to which are associated the maximum deviations for "Loc.3," MKS(B97-1), B3 LYP $\mathrm{GGA}_{\mathrm{GG}}^{0.05}$, and SICVWN. These molecules have not been analyzed with the PBE $0,{ }^{18}$ for which the maximum deviation has been calculated for $\mathrm{CH}_{3} \mathrm{CN}$.

Regarding the results for the ${ }^{17} \mathrm{O}$ shielding, the "Loc.3" approximation performs fairly well (see Table XVI). Its largest deviation is associated with the ${ }^{17} \mathrm{O}$ shielding of $\mathrm{CH}_{3} \mathrm{CHO}$, which, on the contrary, is reproduced quite well by the SIC-VWN. The most difficult case for all the other functionals is represented by $\mathrm{OF}_{2}$, for which the largest ab- 
TABLE XV. ${ }^{15} \mathrm{~N}$ shielding constant (ppm) calculated with the LDA $v_{x c}$.

\begin{tabular}{|c|c|c|c|c|c|c|c|}
\hline Molecule & Loc. 3 & $\mathrm{MKS}^{\mathrm{a}}$ & $\left(\mathrm{B} 3 \mathrm{LYP}_{\mathrm{GGA}}^{0.05}\right)^{\mathrm{b}}$ & $\mathrm{PBE}^{\mathrm{c}}$ & SIC-VWN $^{\mathrm{d}}$ & $A b$ initio & Expt. $^{\mathrm{e}}$ \\
\hline $\mathrm{NH}_{3}$ & 264.6 & 261.6 & 265.0 & 263.1 & 258.4 & $268.8^{\mathrm{f}}$ & $263.5^{\mathrm{h}}$ \\
\hline $\mathrm{CH}_{3} \mathrm{NH}_{2}$ & 264.1 & $\cdots$ & $\cdots$ & 244.0 & 243.4 & $261.2^{\mathrm{g}}$ & $\cdots$ \\
\hline $\mathrm{HNC}$ & 105.2 & $\ldots$ & 105.8 & $\ldots$ & $\ldots$ & $105.5^{\mathrm{f}}$ & $\ldots$ \\
\hline $\mathrm{HCN}$ & -23.8 & -27.0 & -21.1 & -34.9 & -23.5 & $-14.4^{\mathrm{f}}$ & $-20.4^{\mathrm{h}}$ \\
\hline $\mathrm{CH}_{3} \mathrm{CN}$ & -15.1 & $\cdots$ & $\cdots$ & -24.4 & -13.7 & $13.2^{\mathrm{g}}$ & $-9.1^{\mathrm{i}}$ \\
\hline $\mathrm{N}_{2}$ & -64.1 & -65.1 & -55.8 & -76.8 & -73.8 & $-55.7^{\mathrm{f}}$ & $-60.5^{\mathrm{i}}$ \\
\hline $\mathrm{CH}_{2} \mathrm{NN}$ & -39.2 & -46.8 & -38.2 & $\ldots$ & -36.7 & $-31.6^{\mathrm{h}}$ & $-43.4^{\mathrm{h}}$ \\
\hline $\mathrm{CH}_{2} \mathrm{NN}$ & -124.8 & -137.5 & -120.6 & $\cdots$ & -161.9 & $-142.4^{\mathrm{h}}$ & $-149.0^{\mathrm{i}}$ \\
\hline NNO & 104.3 & 98.9 & 103.5 & $\cdots$ & 85.6 & $135.1^{\mathrm{g}}$ & $99.5^{\mathrm{g}}$ \\
\hline NNOO & 8.2 & 6.1 & 12.2 & $\ldots$ & 12.5 & $33.8^{\mathrm{g}}$ & $11.3^{\mathrm{g}}$ \\
\hline
\end{tabular}

${ }^{\mathrm{a}} \mathrm{MKS}(\mathrm{B} 97-1)$ from Ref. 12.

${ }^{\mathrm{b}}$ Reference 13 .

${ }^{\mathrm{c}}$ Reference 18.

${ }^{\mathrm{d}}$ Reference 6 .

${ }^{e}$ Experimental absolute shielding values

${ }^{\mathrm{f}} \mathrm{L}-\mathrm{CCD}$ calculation or expt. from Ref 28.

${ }^{g}$ MBPT(2) calculation or expt. from Ref. 29.

${ }^{\mathrm{h}} \mathrm{CCSD}(\mathrm{T})$ calculation or expt. from Ref. 30.

${ }^{\mathrm{i}}$ Reference 33.

solute deviation is given by the SIC-VWN approach (see Table XVI and Fig. 3).

The problems in the evaluation of the ${ }^{17} \mathrm{O}$ shielding of carbonyl groups are not solved by the use of a more advanced functional: in fact, $\mathrm{HCHO}$ represents the maximum deviation for $\mathrm{MKS}(\mathrm{B} 97-1)$ and $\mathrm{B} 3 \mathrm{LYP}_{\mathrm{GGA}}^{0.05}$ when compared to the $a b$ initio reference, for PBE0 when compared to the experimental reference, and the second largest deviation for SIC-VWN when compared with both $a b$ initio and experimental references.

\section{CONCLUSIONS}

The aim of this work was not only to assess the role of the "Loc.3" approximation as the physical basis of SOSDFPT, but also to establish its capability in the NMR shielding constants calculation compared to the most recent and promising functionals for NMR shielding constant calculations [MKS(B97-1), B3LYP $\mathrm{GGA}^{0,05}$, PBE0, and SIC-VWN]. In order to accomplish this objective, we chose 25 small organic and inorganic molecules to test the "Loc.3" approximation, first against the "traditional" SOS-DFPT approximations (UKS, "Loc.1," and "Loc.2") and then against $\operatorname{MKS}(\mathrm{B} 97-1), \mathrm{B} 3 \mathrm{LYP}_{\mathrm{GGA}}^{0,05}$, PBE0, and SIC-VWN. The results of the first testing show that the "Loc.3" approximation always performs better than UKS and that in case of ${ }^{13} \mathrm{C}$ it performs as well as the "Loc.1" and "Loc.2" approximations. For ${ }^{15} \mathrm{~N}$ the "Loc.3" is superior to all the other SOSDFPT corrections, and for ${ }^{17} \mathrm{O}$ it is better than "Loc. 1 " and very close to "Loc.2." This behavior shows, together with the formal similarity between the equations (see Table I), that "Loc.3" provides a physical basis for SOS-DFPT. We think that the problems encountered with "Loc.3" in the prediction of ${ }^{13} \mathrm{C}$ and of ${ }^{17} \mathrm{O}$ shielding constants in carbonyl groups are partly related to a breakdown of two-level model (2LM) approximation in the TD-DFT calculation.

The role of the asymptotic behavior in the NMR shield-

TABLE XVI. ${ }^{17} \mathrm{O}$ shielding constant calculated with the LDA $v_{x c}$.

\begin{tabular}{crcccccc}
\hline \hline Molecule & Loc. 3 & MKS $^{\mathrm{a}}$ & $\left(_{\text {B3LYP }}^{0.05}\right)^{\mathrm{b}}$ & PBE0 $^{\mathrm{c}}$ & SIC-VWN $^{\mathrm{d}}$ & Ab initio & Expt. $^{\mathrm{e}}$ \\
\hline $\mathrm{CH}_{3} \mathrm{CHO}$ & -381.1 & $\ldots$ & $\ldots$ & $\ldots$ & -273.0 & $-291.7^{\mathrm{f}}$ & $\cdots$ \\
$\mathrm{CH}_{3} \mathrm{COCH}$ & -325.4 & $\ldots$ & $\ldots$ & -330.2 & -259.3 & $-279.8^{\mathrm{f}}$ & $\cdots$ \\
$\mathrm{CH}_{3} \mathrm{OH}$ & 326.1 & $\ldots$ & $\ldots$ & 334.7 & $\cdots$ & $350.6^{\mathrm{f}}$ & $\cdots$ \\
$\mathrm{HCHO}$ & -430.3 & -360.3 & -346.4 & -422.2 & -335.3 & $-418.0^{\mathrm{g}}$ & $-375.0^{\mathrm{b}}$ \\
$\mathrm{CO}$ & -20.9 & -50.8 & -44.4 & -70.0 & -43.1 & $-57.4^{\mathrm{g}}$ & $-36.7 \pm 17.2^{\mathrm{f}}$ \\
$\mathrm{CO}$ & 213.3 & 224.2 & 223.2 & 220.0 & 227.6 & $241.0^{\mathrm{f}}$ & $243.4^{\mathrm{b}}$ \\
$\mathrm{H}_{2} \mathrm{O}$ & 335.6 & 330.2 & 334.4 & 328.9 & 324.0 & $335.4^{\mathrm{g}}$ & $357.6 \pm 17.2^{\mathrm{f}}$ \\
$\mathrm{H}_{2} \mathrm{O}_{2}$ & 135.6 & $\ldots$ & 119.0 & $\cdots$ & 89.3 & $133.9^{\mathrm{g}}$ & $\cdots$ \\
$\mathrm{N}_{2} \mathrm{O}$ & 181.8 & 190.1 & 192.0 & $\cdots$ & 199.4 & $206.2^{\mathrm{f}}$ & $200.5^{\mathrm{i}}$ \\
$\mathrm{OF}_{2}$ & -529.2 & -505.0 & -502.5 & $\cdots$ & -697.0 & $-479.8^{\mathrm{f}}$ & $-473.1^{\mathrm{b}}$ \\
\hline \hline
\end{tabular}

${ }^{\mathrm{a}} \mathrm{MKS}(\mathrm{B} 97-1)$ from Ref. 12.

${ }^{\mathrm{b}}$ Reference 13 .

${ }^{\mathrm{c}}$ Reference 18 .

${ }^{\mathrm{d}}$ Reference 6

${ }^{e}$ Experimental absolute shielding values.

${ }^{\mathrm{f}} \mathrm{CCSD}(\mathrm{T})$ calculation or expt. from Ref. 30.

${ }^{\mathrm{g}} \mathrm{L}-\mathrm{CCD}$ calculation or expt. from Ref. 28.

${ }^{\mathrm{h}} \mathrm{MBPT}(2)$ calculation or expt. from Ref. 29. 
ing calculations has also been the subject of further testing. We were able to determine that the use of a functional with a corrected asymptotic behavior does not influence dramatically the accuracy of the results, in agreement with the observations reported in Refs. 4 and 12. The only exceptions are given by the case of $\mathrm{OF}_{2}$, where the ${ }^{17} \mathrm{O}$ shielding is considerably improved, and by the case of $\mathrm{CH}_{3} \mathrm{CN}$ and $\mathrm{N}_{2}$, where the ${ }^{15} \mathrm{~N}$ shielding is considerably worsen. Therefore we decided to compare the "Loc.3" calculations, obtained using only the LDA functional, to the results from the MKS(B97-1), B3LYP ${ }_{\text {GGA }}^{0,05}$ PBE0, and SIC-VWN functionals. The results have been determined to be very promising particularly in the case of ${ }^{15} \mathrm{~N}$, where "Loc.3" offers a very competitive performance. The results obtained for ${ }^{13} \mathrm{C}$ and ${ }^{17} \mathrm{O}$ are greatly affected by problems with the carbonyl groups, which do not seem to be completely solved by the use of the more advanced functionals considered in this work. Therefore, we think that the accuracy of the SOSDEPT calculations can be greatly improved not only by the use of a more sophisticated functional, but also by the elimination of the 2LM from the "Loc.3" approximation. The latter will allow a correct description of the spatial multiplets, but it would also greatly reduce the computational efficiency, which is one of the most significant advantages of SOS-DFPT.

\section{ACKNOWLEDGMENTS}

Financial support through grants from the Natural Sciences and Engineering Research Council (NSERC) of Canada, the Canadian Institute for Photonics Innovation (CIPI), the Fonds pour la formation des chercheurs et l'aide à la recherche (FCAR) of Québec, and (in the case of E.F.) the Government of Sardinia is gratefully acknowledged. The authors would like to thank Dr. D.J. Tozer and Dr. T. Ziegler for valuable feedback, and E.F. would also like to thank A. Schiavetti for his helpful advice on a draft of the manuscript.

${ }^{1}$ V. G. Malkin, O. L. Malkina, L. A. Eriksson, and D. R. Salahub, in Modern Density Functional Theory: A Tool for Chemistry, Vol. 2 of Theoretical and Computational Chemistry, edited by J. M. Seminario and P. Politzer (Elsevier Science B.V., Amsterdam, 1995), p. 273.

${ }^{2}$ G. Vignale, M. Rasolt, and D. J. W. Geldart, Adv. Quantum Chem. 21, 235 (1990).

${ }^{3}$ V. G. Malkin, O. L. Malkina, M. E. Casida, and D. R. Salahub, J. Am. Chem. Soc. 116, 5898 (1994).
${ }^{4}$ P. J. Wilson, R. D. Amos, and N. C. Handy, Mol. Phys. 97, 757 (1999).

${ }^{5}$ L. Olsson and D. Cremer, J. Phys. Chem. 100, 16881 (1996).

${ }^{6}$ S. Patchkovskii, J. Autschbach, and T. Ziegler, J. Chem. Phys. 115, 26 (2001).

${ }^{7}$ T. Helgaker, M. Jaszuński, and K. Ruud, Chem. Rev. 99, 293 (1999).

${ }^{8}$ C. Jamorski, M. E. Casida, and D. R. Salahub, J. Chem. Phys. 104, 5134 (1996)

${ }^{9}$ M. E. Casida, in Recent Advances in Density Functional Methods, edited by D. P. Chong (Singapore, World Scientific, 1995), Pt. I, pp. 155-192.

${ }^{10}$ E. Fadda, M. E. Casida, and D. R. Salahub, Int. J. Quantum Chem. 91, 67 (2003).

${ }^{11}$ S. Hirata and M. Head-Gordon, Chem. Phys. Lett. 314, 291 (1999).

${ }^{12}$ P. J. Wilson and D. J. Tozer, Chem. Phys. Lett. 337, 341 (2001).

${ }^{13}$ P. J. Wilson, R. D. Amos, and N. C. Handy, Chem. Phys. Lett. 312, 475 (1999).

${ }^{14}$ A. D. Becke, J. Chem. Phys. 98, 5648 (1993).

${ }^{15}$ J. P. Perdew, K. Burke, and M. Ernzenhof, Phys. Rev. Lett. 77, 3865 (1996).

${ }^{16}$ J. P. Perdew, K. Burke, and M. Ernzenhof, Phys. Rev. Lett. 78, 1396(E) (1997).

${ }^{17}$ C. Adamo, G. E. Scuseria, and V. Barone, J. Chem. Phys. 111, 2889 (1999).

${ }^{18}$ C. Adamo and V. Barone, Chem. Phys. Lett. 298, 113 (1998).

${ }^{19}$ N. F. Ramsey, Phys. Rev. 78, 699 (1950).

${ }^{20}$ N. F. Ramsey, Phys. Rev. 91, 303 (1953).

${ }^{21}$ J. Autshbach, T. Ziegler, S. J. A. Gisbergen, and E. J. Baerends, J. Chem. Phys. 116, 891 (2002).

${ }^{22}$ J. Autshbach and T. Ziegler, J. Chem. Phys. 116, 6930 (2002). D. R. Salahub and J.-P. Daudey, J. Chem. Phys. 113, 7062 (2000). L. G. M. Pettersson, Theor. Chim. Acta 97, 14 (1997).

${ }^{23}$ A. St-Amant and D. R. Salahub, Chem. Phys. Lett. 169, 387 (1990); Alain St-Amant, Ph.D. thesis, University of Montreal, 1992; M. E. Casida, C. Daul, A. Goursot, A. Koester, L. G. M. Pettersson, E. Proynov, A. StAmant, and D. R. Salahub principal authors, S. Chretien, H. Duarte, N. Godbout, J. Guan, C. Jamorski, M. Leboeuf, V. Malkin, O. Malkina, M. Nyberg, L. Pedocchi, F. Sim, and A. Vela (contributing authors), computer code DEMON-Ks, version 3.5, deMon Software, 1998.

${ }^{24}$ W. Kutzelnigg, U. Fleischer, and M. Schindler, NMR 213, 165 (1991).

${ }^{25}$ S. H. Vosko, L. Wilk, and M. Nusair, Can. J. Phys. 58, 1200 (1980).

${ }^{26}$ M. E. Casida, K. C. Casida, and D. R. Salahub, Int. J. Quantum Chem. 70, 933 (1998).

${ }^{27}$ M. E. Casida and D. R. Salahub, J. Chem. Phys. 113, 8918 (2000).

${ }^{28}$ S. M. Cybulski and D. M. Bishop, J. Chem. Phys. 106, 4082 (1997).

${ }^{29}$ J. Gauss, J. Chem. Phys. 99, 3629 (1993).

${ }^{30}$ J. Gauss and J. F. Stanton, J. Chem. Phys. 103, 3561 (1995).

${ }^{31}$ J. Gauss and J. F. Stanton, J. Chem. Phys. 104, 2574 (1996).

${ }^{32}$ A. K. Jameson and C. J. Jameson, Chem. Phys. Lett. 134, 461 (1987).

${ }^{33}$ C. J. Jameson, A. K. Jameson, D. Oppusunggu, P. M. Burrell, and J. Mason, J. Chem. Phys. 74, 81 (1981).

${ }^{34}$ A. D. Becke, J. Chem. Phys. 107, 8554 (1997).

${ }^{35}$ F. A. Hamprecht, A. J. Cohen, D. J. Tozer, and N. C. Handy, J. Chem. Phys. 109, 6264 (1998).

${ }^{36}$ N. C. Handy and D. J. Tozer, Mol. Phys. 94, 707 (1998). 